\title{
Neurophenomenology: \\ An Introduction for Neurophilosophers
}

Evan Thompson, Antoine Lutz, and Diego Cosmelli

Forthcoming in: Andy Brook and Kathleen Akins (eds.), Cognition and the Brain: The Philosophy and Neuroscience Movement.

New York and Cambridge: Cambridge University Press.

\section{Introduction}

One of the major challenges facing neuroscience today is to provide an explanatory framework that accounts for both the subjectivity and neurobiology of consciousness. Although neuroscientists have supplied neural models of various aspects of consciousness, and have uncovered evidence about the neural correlates of consciousness (or NCCs), ${ }^{1}$ there nonetheless remains an 'explanatory gap' in our understanding of how to relate neurobiological and phenomenological features of consciousness. This explanatory gap is conceptual, epistemological, and methodological:

- An adequate conceptual framework is still needed to account for phenomena that (i) have a first-person, subjective-experiential or phenomenal character; (ii) are (usually) reportable and describable (in humans); and (iii) are neurobiologically realized. ${ }^{2}$

- The conscious subject plays an unavoidable epistemological role in characterizing the explanadum of consciousness through first-person descriptive reports. The experimentalist is then able to link first-person data and third-person data. Yet the generation of first-person data raises difficult epistemological issues about the relation of second-order awareness or meta-awareness to first-order experience (e.g.,

\footnotetext{
${ }^{1}$ For recent neural models of consciousness see Tononi and Edelman (1998), Freeman (1999a, 1999b), Dehaene and Naccache (2001), Parvizi and Damasio (2001), Engel and Singer (2001), Crick and Koch (2003). For NCC evidence see Metzinger (2000) and Rees, Kreiman, and Koch (2002).

${ }^{2}$ For a recent overview of this aspect of the explanatory gap see Roy, Petitot, Pachoud, and Varela (1999).
} 
whether second-order attention to first-order experience inevitably affects the intentional content and/or phenomenal character of first-order experience). ${ }^{3}$

- The need for first-person data also raises methodological issues (e.g., whether subjects should be naïve or phenomenologically trained).

Neurophenomenology is a neuroscientific research program whose aim is to make progress on these issues associated with the explanatory gap. ${ }^{4}$ In this paper we give an overview of the neurophenomenological approach to the study of consciousness.

Whereas 'neurophilosophy' is rooted in analytic philosophy (Churchland 1986, 2002), neurophenomenology, as its name suggests, has strong roots in the tradition of phenomenological philosophy. In recent years a new current of phenomenological philosophy has emerged in Europe and North America, one that goes back to the source of phenomenology in Husserl's philosophy, but is influenced by cognitive science and analytic philosophy of mind, and aims to contribute to these fields (see Petitot, Varela, Pachoud, and Roy 1999; Thompson 2004; and the new journal Phenomenology and the Cognitive Sciences). Neurophenomenology belongs to this current. Our aim in this paper is to communicate the main ideas of neurophenomenology in the form of a review for a neurophilosophical audience, who may not be as familiar with phenomenology and its potential in relation to the neuroscientific study of consciousness. ${ }^{5}$

Neurophenomenology also grows out of the enactive approach in cognitive science, which has strong ties to phenomenology (Varela, Thompson, and Rosch 1991). We discuss this cognitive science background of neurophenomenology in Section 2. In Section 3 we discuss the motivation for neurophenomenology in current affectivecognitive neuroscience. Section 4 is devoted to explaining phenomenological conceptions

\footnotetext{
${ }^{3}$ See Hurlbert and Heavey (2001), Jack and Shallice (2001), Jack and Roepstorff (2002), Lambie and Marcel (2002), and Schooler (2002).

${ }^{4}$ Neurophenomenology was introduced by Varela in the mid 1990s (Varela 1996, 1997b, 1999). For subsequent discussions see Bitbol (2002), Le Van Quyen and Petitmengin (2002), Lutz (2002), Rudrauf, Lutz, Cosmelli, Lachaux, and Le Van Quyen (2003), Varela and Thompson (2003), Lutz and Thompson (2003), and Hanna and Thompson (2004).

${ }^{5}$ For an introduction to phenomenology written for a cognitive science audience see Thompson and Zahavi (in press).
} 
of consciousness. Section 5 gives an overview of neurodynamical approaches to the study of large-scale brain activity. Section 6 is concerned with first-person methods of investigating experience. Section 7 reviews two experimental, neurophenomenological studies of ongoing conscious states and large-scale brain activity. Section 8 focuses on research on the neural correlates of consciousness, as seen from a neurophenomenological perspective. Section 9 concludes the paper by returning to the issue of the explanatory gap.

\section{The Enactive Approach}

Neurophenomenology is an offshoot of the enactive approach in cognitive science (Varela, Thompson, and Rosch 1991). The word 'enactive' was coined by Varela in order to describe and unify under one heading several related ideas. The first idea is that organisms are autonomous agents that actively generate and maintain their identities, and thereby define their own cognitive domains. The second idea is that the nervous system is an autonomous system: it actively generates and maintains its own coherent patterns of activity, according to its operation as an organizationally closed sensorimotor network of interacting neurons. The third idea is that cognitive structures emerge from such recurrent sensorimotor couplings of body, nervous system, and environment. ${ }^{6}$ Like phenomenology, the enactive approach thus emphasizes that the organism defines its own point of view on the world. As we will see, this autonomy perspective has important

\footnotetext{
${ }^{6}$ Varela thought of the name 'the enactive approach' in the summer of 1986 in Paris when Varela and Thompson began writing The Embodied Mind (Varela, Thompson, and Rosch 1991). Earlier he had been using 'the hermeneutic approach' to emphasize the affiliation of his ideas to the philosophical school of hermeneutics — an affiliation also emphasized by other theorists of embodied cognition at the time (see Varela, Thompson, and Rosch 1991, pp. 149-150). The first and second ideas summarized above were presented in Varela's 1979 book, Principles of Biological Autonomy. They were developed with Humberto Maturana, and grew out of Maturana's earlier work on the biology of cognition (Maturana 1969, 1970; Maturana and Varela 1980, 1987). The third idea was presented by Varela, Thompson, and Rosch (1991), by Thompson, Palacios, and Varela (1992), and was elaborated by Varela in a number of subsequent papers (e.g., Varela 1991, 1997a).
} 
implications for how we conceptualize brain activity and its relationship to mental activity, including consciousness.

Let us start with the notion of an autonomous system. 'Autonomous' literally means self-governing or conforming to its own law. In the theory of complex (nonlinear dynamic) systems, 'autonomous' is used to describe a system that is a self-generating and self-maintaining whole, such as a cell or multicellular organism (Varela 1979; Varela and Bourgine 1991). In general, to specify any system one needs to describe its organization - the set of relations that defines it as a system. In a complex dynamic system, the relevant relations are ones between dynamic processes. An autonomous system is a network of processes, in which (i) the processes recursively depend on each other for their generation and their realization as a network; and (ii) the processes constitute the system as a unity in whatever domain they exist (Varela 1979, p. 55). The paradigmatic example is a living cell. The constituent processes in this case are chemical; their recursive interdependence takes the form of a self-producing, metabolic network that also produces its own membrane; and this network constitutes the system as a unity in the biochemical domain. This kind of self-production in the biochemical domain is known as autopoiesis (Maturana and Varela 1980). Autopoiesis is the fundamental and paradigmatic case of biological autonomy.

According to Varela, an autonomous system can be precisely defined as a system that has organizational closure and operational closure (Varela 1979, pp. 55-60). The term 'closure' does not mean that the system is materially and energetically closed to the outside world (which of course is impossible). On the contrary, autonomous systems are thermodynamically far from equilibrium systems, which incessantly exchange matter and energy with their surroundings. 'Organizational closure' describes the self-referential (circular and recursive) network of relations that defines the system as a unity. At any given instant or moment, this self-referential network must be maintained, otherwise the system is no longer autonomous and no longer viable in whatever domain it exists. 'Operational closure' describes the recursive, re-entrant, and recurrent dynamics of the system. The system changes state on the basis of its self-organizing dynamics (in coupling with an environment), and the product of its activity is always further selforganized activity within the system (unless its operational closure is disrupted and it 
disintegrates). ${ }^{7}$ Biological examples abound—single cells, microbial communities, nervous systems, immune systems, multicellular organisms, ecosystems, and so on. Such systems need to be seen as sources of their own activity, and as specifying their own informational or cognitive domains, not as transducers or functions for converting input instructions into output products. In other words, the autonomous nature of these systems needs to be recognized.

In the case of the brain and nervous system, this autonomous systems perspective implies that the endogenous, self-organizing dynamics of neural activity should be the reference point for relating brain processes to mental processes. The overall organization of the brain reflects a principle of reciprocity: if area $\mathrm{A}$ connects to area $\mathrm{B}$, then there are reciprocal connections from B to A (Varela 1995; Varela, Lachaux, Rodriguez, and Martinerie 2001). Moreover, if B receives most of its incoming influence from A, then it sends the larger proportion of its outgoing activity back to A, and only a smaller proportion onward (Freeman 2000, p. 224). Nevertheless, traditional neuroscience has tried to map brain organization onto a hierarchical, input-output processing model, in which the sensory end is taken as the starting point. Perception is described as proceeding through a series of feedforward or bottom-up processing stages, and top-down influences are equated with back-projections or feedback from higher to lower areas. Walter Freeman (1999a, 1999b, 2000) aptly describes this view as the 'passivist-cognitivist view' of the brain. From an enactive viewpoint, things look rather different. Brain processes are recursive, re-entrant, and self-activating, and do not start or stop anywhere. Instead of treating perception as a later stage of sensation and taking the sensory receptors as the starting point for analysis, the enactive approach treats perception, emotion, and cognition as dependent aspects of intentional action, and takes the brain's self-generated, endogenous activity as the starting point for analysis. This activity arises

\footnotetext{
7 'Closure' is used here in its algebraic sense: An operation $K$ exhibits closure in a domain $D$ if every result of its operation yields results within $D$. Thus the operation of a system has operational closure if the results of its activity remain within the system itself. This notion of operational closure has nothing to do with the idea of a materially closed system - a system that is closed to interactions with what lies beyond it. Autonomous systems are and must be coupled to their surroundings; the issue is the nature of the dynamics that defines them and on the basis of which they interact with what lies beyond them.
} 
far from the sensors - in the frontal lobes, limbic areas, or temporal and associative cortices - and reflects the organism's states of expectancy, preparation, emotional tone, attention, and so on, states necessarily active at the same time as the sensory inflow, and that shape that inflow in a meaningful way (Varela, Lachaux, Rodriguez, and Martinerie 2001; Engel, Fries, and Singer 2001). Freeman describes this view as the 'activistpragmatist' view of the brain. Whereas a passivist-cognitivist view would describe such internal states as acting in a 'top-down' manner on sensory processing, from an activistpragmatist or enactive view, 'top down' and 'bottom up' are simply heuristic terms for what in reality is a large-scale network that integrates incoming and endogenous activities on the basis of its own internally established reference points (Varela, Lachaux, Rodriguez, and Martinerie 2001). Hence from an enactive viewpoint, we need to look to this large-scale dynamic network in order to understand how cognition, intentional action, and consciousness emerge through self-organizing neural activity.

Yet understanding such large-scale dynamic activity poses considerable challenges for the experimentalist, because it is highly labile and variable from trial to trial, and cannot be fully controlled from the outside. Similarly, mental activity is variable from moment to moment, in the form of fluctuations in emotion, quality of attention, motivation, and so forth. Thus a large part of the subject's internal activity at both psychological and experiential levels is externally uncontrollable and therefore unknown. The working hypothesis of neurophenomenology is that disciplined, first-person accounts of the phenomenology of mental processes can provide additional, valid information about these externally uncontrollable aspects of mental activity, and that this information can be used to detect significant patterns of dynamic activity at the neural level.

\section{Neurophenomenology and Affective-Cognitive Neuroscience}

The enactive approach in its neurophenomenological development converges with the growing recognition in affective-cognitive neuroscience that much more detailed and refined first-person descriptions of conscious experience are needed in order to characterize the explanadum of consciousness and relate it to the complexity of brain activity (Jack and Roepstorff 2002, 2003; Lutz and Thompson 2003).

Neurophenomenology stresses the importance of gathering first-person data from 
phenomenologically trained subjects as a heuristic strategy for describing and quantifying the physiological processes relevant to consciousness. The general approach, at a methodological level, is (i) to obtain richer first-person data through disciplined phenomenological explorations of experience, and (ii) to use these original first-person data to uncover new third-person data about the physiological processes crucial for consciousness. Thus one central aim of neurophenomenology is to generate new data by incorporating refined and rigorous phenomenological explorations into the experimental protocols of neuroscientific research on consciousness.

The term 'neurophenomenology' pays homage to phenomenological traditions in both Western philosophy (Petitot, Varela, Pachoud, and Roy 1999; Moran 2000) and Asian philosophy (Gupta 1998; Wallace 1998; Williams 1998). Phenomenology in this broad sense can be understood as the project of providing a disciplined characterization of the phenomenal invariants of lived experience in all of its multifarious forms. By 'lived experience' we mean experiences as they are lived and verbally articulated in the first-person, whether they be lived experiences of perception, action, memory, mental imagery, emotion, attention, empathy, self-consciousness, contemplative states, dreaming, and so on. By 'phenomenal invariants' we mean categorical and structural features of experience that are phenomenologically describable both across and within the various forms of lived experience. By 'disciplined characterization' we mean a phenomenological mapping of experience based on the use of both first-person methods for increasing one's sensitivity to one's experience, and second-person methods for facilitating this process and eliciting descriptive accounts of experience (Varela and Shear 1999a; Petitmengin 2001; Depraz, Vermersch, and Varela 2003). The importance of this sort of phenomenological investigation of experience for cognitive science was already proposed and extensively discussed by Varela, Thompson, and Rosch (1991) as an integral part of the enactive approach. It was then subsequently elaborated by Varela (1996, 1997b, 1999) into the neuroscientific research program of neurophenomenology.

The use of first-person and second-person phenomenological methods to obtain original and refined first-person data is central to neurophenomenology. It seems true both that people vary in their abilities as observers and reporters of their own experiences, and that these abilities can be enhanced through various methods. First- 
person methods are disciplined practices subjects can use to increase their sensitivity to their own experiences at various time-scales (Varela and Shear 1999a; Depraz, Varela, and Vermersch 2003). These practices involve the systematic training of attention and self-regulation of emotion. Such practices exist in phenomenology, psychotherapy, and contemplative meditative traditions. Using these methods, subjects may be able to gain access to aspects of their experience, such as transient affective state and quality of attention, that otherwise would remain unnoticed and unavailable for verbal report. The experimentalist, on the other hand, using phenomenological accounts produced with these methods, may be able to gain access to physiological processes that otherwise would remain opaque, such as the variability in brain response as recorded in neuroimaging experiments (see Section 7). Thus at a methodological level, the neurophenomenological rationale for using first-person methods is to generate new data-both first-person and third-person-for the science of consciousness.

The working hypothesis of neurophenomenology in an experimental context is that phenomenologically precise first-person data produced by employing firstperson/second-person methods provide strong constraints on the analysis and interpretation of the physiological processes relevant to consciousness. In addition, thirdperson (biobehavioural) data produced in this manner might eventually constrain firstperson data, so that the relationship between the two would become one of dynamic reciprocal constraints (Varela 1996; Lutz 2002). Reciprocal constraints means not only (i) that the subject is actively involved in generating and describing specific phenomenal invariants of experience, and (ii) that the neuroscientist is guided by these first-person data in the analysis and interpretation of physiological data, but also (iii) that the (phenomenologically enriched) neuroscientific analyses provoke revisions and refinements of the phenomenological accounts, as well as facilitate the subject's becoming aware of previously inaccessible or phenomenally unavailable aspects of his or her mental life. Preliminary examples of this third step can be found in neurophenomenological studies of epilepsy (Le Van Quyen and Petitmengin 2002) and pain (Price, Barrell, and Rainville 2001).

To establish such reciprocal constraints, both an appropriate candidate for the physiological basis of consciousness and an adequate theoretical framework to 
characterize it are needed. Neurophenomenology is guided by the theoretical proposal (discussed in Section 5) that the best current candidate for the neurophysiological basis of consciousness is a flexible repertoire of dynamic large-scale neural assemblies that transiently link multiple brain regions and areas. This theoretical proposal is shared by a number of researchers, though specific models vary in their details (Varela 1995; Tononi and Edelman 1998; Freeman 1999a, 1999b; Engel and Singer 2001). In this approach, the framework of dynamic systems theory is essential for characterizing the neural processes relevant to consciousness (see Le Van Quyen 2003). Neurophenomenology is thus based on the synergistic use of three fields of knowledge:

1. (NPh1) First-person data from the careful examination of experience with specific first-person methods.

2. (NPh2) Formal models and analytic tools from dynamic systems theory, grounded on an enactive approach to cognition.

3. (NPh3) Neurophysiological data from measurements of large-scale, integrative processes in the brain.

The remaining sections of this paper cover topics that fall within this threefold schema.

\section{Concepts of Consciousness}

A number of different concepts of consciousness can be distinguished in current neuroscientific and philosophical discussions of consciousness:

- Creature consciousness: consciousness of an organism as a whole insofar as it is awake and sentient (Rosenthal 1997).

- Background consciousness versus state consciousness: overall states of consciousness, such as being awake, being asleep, dreaming, being under hypnosis, and so on (Hobson 1999), versus specific conscious mental states individuated by their contents (Rosenthal 1997; Chalmers 2000). (The coarsest-grained state of background consciousness is sometimes taken to be creature consciousness (Chalmers 2000).) 
- Transitive consciousness versus intransitive consciousness: object-directed consciousness (consciousness-of), versus non-object-directed consciousness (Rosenthal 1997).

- Access consciousness: mental states whose contents are accessible to thought and verbal report (Block 2001). According to one important theory, mental contents are access conscious when they are 'globally available' in the brain as contents of a 'global neuronal workspace' (Dehaene and Naccache 2001; Baars 2002).

- Phenomenal consciousness: mental states that have a subjective-experiential character (there is something 'it is like' for the subject to be in such a state) (Nagel 1979; Block 2001).

- Introspective consciousness: meta-awareness or second-order awareness of a firstorder conscious state. The second-order conscious state is usually understood as a form of access consciousness, and the first-order state as a phenomenally conscious state (Jack and Shallice 2001; Jack and Roepstorff 2002; Lambie and Marcel 2002).

- Pre-reflective self-consciousness: primitive self-consciousness; self-referential awareness of subjective experience that does not require active reflection or introspection (Wider 1997; Williams 1998; Gupta 1998; Zahavi 1999; Kriegel 2003).

The relationships of these concepts to one another are unclear and currently the subject of debate. A great deal of debate has centered on the relation between access consciousness and phenomenal consciousness. ${ }^{8}$ Although a notional distinction can be drawn between awareness in the sense of cognitive access, and awareness in the sense of subjective experience, it is not clear whether this distinction corresponds to a difference in kind of awareness, or merely a difference in degree of awareness. Put another way, it is not clear whether 'access consciousness' and 'phenomenal consciousness' are two separate concepts, or that if they are, they pick out two different properties, rather than one and the same property. Some theorists argue that it is conceptually possible for there to be phenomenally conscious contents that are inaccessible to thought and verbal report (Block 1997, 2001). Others argue that this notion of subjective experience without access is incoherent, and that all consciousness is access consciousness (Dennett 1997, 2001).

\footnotetext{
${ }^{8}$ See Block (1997) and replies by Dennett (1997), Chalmers (1997), Church (1997) and Burge (1997).
} 
How does this debate look from a broadly phenomenological perspective? Before addressing this question, we need to review two concepts central to phenomenology, the concepts of intentionality and pre-reflective self-consciousness.

\section{Intentionality}

According to phenomenology, conscious states and processes are intentional in a broad sense: they aim toward or intend something beyond themselves. Phenomenologists distinguish different types of intentionality. In a narrow sense, intentionality is defined as object-directedness. In a broader sense, intentionality is defined as openness toward the world or what is 'other' ('alterity'). In either case, the emphasis is on denying that the mind is self-enclosed (Zahavi 2003, 2004).

Object-directed experiences are ones in which we are conscious of something in a more-or-less determinate sense. When we see, we see something; when we remember, we remember something; when we hope or fear, we hope for or fear something, and so on. These kinds of transitive consciousness are characterized by the intending of an object (which need not exist). 'Object' in its etymological sense means something that stands before one. Something standing before one lies beyond, over against, or outside of one. Object-directed experiences can thus be understood as experiences in which one is conscious as of something distinct from oneself as a present subject, whether this be a past event remembered, a thing perceived in the settings around one, a future event feared or hoped for, and so on.

Phenomenologists call this act-object relation the correlational structure of intentionality. 'Correlational' does not mean the constant conjunction of two terms that could be imagined to exist apart, but the invariant structure of intentional act/intentional object. Object-directed intentional experiences necessarily comprise these two inseparable poles. In Husserlian phenomenological language, these two poles of experience are known as the noema (the object as experienced) and the noesis (the mental act that intends the object).

Many kinds of experience, however, are not object-directed in this sense. Such experiences include bodily feelings of pain, moods such as undirected anxiety, depression, and elation, and 'absorbed skilful coping' (Dreyfus 1991) in everyday life. 
These types of experience either are not or need not be 'about' any intentional object. They are not directed toward a transcendent object, in the sense of something experienced as standing over against oneself as a distinct subject. Put another way, they do not have a subject-object structure.

Philosophers who limit intentionality to object-directedness or transitive consciousness deny that experiences like these are intentional (e.g., Searle 1983). Nevertheless, they do qualify as intentional in the broader phenomenological sense of being open to what is other or having a world-involving phenomenal character. Thus bodily feelings such as pain are not self-enclosed without openness to the world. On the contrary, they present things in a certain affective light or atmosphere, and thereby deeply influence how we perceive and respond to things. A classic example is Sartre's discussion of feeling eyestrain and fatigue as a result of reading late into the night (1956, pp. 332-333). ${ }^{9}$ The feeling manifests first not as an intentional object of some higherorder state of transitive consciousness, but as a trembling of the eyes and a blurriness of the words on the page. One's body and immediate environment disclose themselves in a certain manner through the feeling. In the case of moods, although they are not objectdirected in the manner of intentional emotions, such as a feeling of sympathy for a loved one or a feeling of envy for a rival, they are nonetheless hardly self-enclosed without reference to the world. On the contrary, as Heidegger (1996) analyzes at length in Being and Time, moods reveal our embeddedness in the world, and (as he sees it) make possible more circumscribed forms of directedness in everyday life. In absorbed skilful activities, such as driving, dancing, or writing, one's experience is not that of relating to a distinct intentional object, but of being engaged and immersed in a fluid activity, which takes on a subject-object structure only during moments of breakdown or disruption (see Dreyfus and Dreyfus 1982; Dreyfus 1991, 2002). ${ }^{10}$

These cases of intransitive or non-object-directed experience illustrate the difference between a thematic, explicit, or focal, object-directed mode of consciousness,

\footnotetext{
${ }^{9}$ Our use of this example is due to Gallagher (1986) and Zahavi (2004).

${ }^{10}$ A more difficult case is certain contemplative or meditative states, in which it is reported that awareness is experienced as without an object (Foreman 1990; Austin 1998). How to describe these states in relation to the phenomenological notion of intentionality is a complicated issue that we cannot pursue here.
} 
and a non-reflective, implicit, tacit sensibility. This intransitive sensibility constitutes our primary openness to the world. Husserl and Merleau-Ponty use the term 'operative intentionality' to describe this kind of intentionality, because it is constantly operative in a pre-reflective and involuntary way, without being engaged in any explicit cognitive project (Husserl 2001, p. 206; Merleau-Ponty 1962, p. xviii).

Two additional distinctions are important in the context of distinguishing objectdirected and transitive intentionality from intransitive and operative intentionality. ${ }^{11}$ The first is between activity and passivity. Activity means taking a cognitive position in acts of attending, judging, valuing, wishing, and so on. Passivity means being involuntarily affected, moved, and directed. Whenever one is active, one is also passive, because to be active is to react to something that has affected one. Every kind of active position-taking presupposes a prior (and ongoing) passivity. The second distinction is between affection and receptivity. Affection belongs to the sphere of passivity, and means being affectively influenced or perturbed. Receptivity means responding to an involuntary affection (affective influence) by noticing or turning toward it. Every receptive action presupposes a prior affection. As Dan Zahavi explains: "Receptivity is taken to be the first, lowest, and most primitive type of intentional activity, and consists in responding to or paying attention to that which is affecting us passively. Thus, even receptivity understood as a mere 'I notice' presupposes a prior affection" (Zahavi 1999, p. 116). In other words, receptivity is the lowest active level of attention, at the fold, as it were, between passivity and activity (a differentiation that can be made only dynamically and relatively, not statically and absolutely). To be affected by something is not yet to be presented with an intentional object, but to be drawn to turn one's attention toward whatever exerts the affection. Thus whatever comes into relief in experience through attention must have already been affecting one, and must have some kind of 'affective force' or 'affective allure' in relation to one's attention and motivations. Attentiveness at any level is motivated in virtue of something's affective allure, an idea familiar to psychologists as motivated attention (Derryberry and Tucker 1994). Depending on the nature and force of the allure, as well as one's motivations, one may yield to the allure passively or

\footnotetext{
${ }^{11}$ These distinctions emerge in Husserl's lectures during the 1920s on the phenomenology of 'passive synthesis' in experience. See Husserl (2001).
} 
involuntarily, voluntarily turn one's attention toward it, or have one's attention captured or repulsed by it. Allure implies a dynamic gestalt or figure-ground structure: something becomes noticeable, at whatever level of attentiveness, due to the strength of its allure, emerging into affective prominence, salience, or relief, while other things become less noticeable due to comparative weakness of their allure (Husserl 2001, p. 211). Whatever exercises affective allure without our turning to it attentively (even at a level of bare noticing) is said to be 'pregiven', and whatever succeeds in gaining attention is said to be 'given'. Thus the given - the mode or way in which something appears to one- has to be understood dynamically as emergent in relation to the pregiven. ${ }^{12}$ This dynamic interplay of passivity and activity, affection and receptivity, expresses a constantly operative and affectively 'saturated intentionality' (Steinbock 1999). Object-directed and transitive intentional experiences emerge only against the background of this pre-cognitive, operative intentionality (Merleau-Ponty 1962, p. xviii).

\section{Pre-reflective Self-consciousness}

As mentioned above, the term 'phenomenal consciousness' refers to mental states that have a subjective and experiential character. In Nagel's words, for a mental state to be conscious is for there to be something it is like for the subject to be in that state (Nagel

\footnotetext{
${ }^{12}$ Does Husserl's phenomenology imply belief in an uninterrupted and theory-neutral 'given' in experience, the so-called 'philosophical myth of the given'? This is a difficult and complicated question. There is not one but several different notions of the 'given' in philosophy, and Husserl's thought developed considerably over the course of his life, such that he held different views at different times regarding what might be meant by the 'given'. Suffice it to say that it is mistaken to label Husserl as a philosopher of the 'given' in the sense originally targeted by Wilfrid Sellars (1956) or by critics of the notion of theory-neutral observation, such as Thomas Kuhn (1970), for at least these four reasons: First, the given in the phenomenological sense is not non-intentional sense-data, but the world as it appears to us. Second, the phenomenality of the world is not understandable apart from the constitutive relation subjectivity and consciousness bear to it. Third, as discussed above, whatever counts as 'given' has to be seen as dynamically emergent in relation to what is 'pregiven', and the transition from pregiven to given depends on the subject's motivations, interests, and attentional capacities. Finally, the given comprises not simply phenomenal presence in a narrow sense (what is facing me right now), but also absence and possibility (the sides of the bottle I cannot see, but that are available for me to see through movement). For recent discussions of some of these issues see Botero (1999), Steinbock (1999), and Roy (2004).
} 
1979). Various notions are used to describe the properties characteristic of phenomenal consciousness - qualia, sensational properties, phenomenal properties, the subjective character of experience - and there is considerable debate about the relation between these properties and other properties of mental states, such as their representational content or their being cognitively accessible to thought and verbal report (access consciousness). From a phenomenological perspective, Nagel's original term, 'the subjective character of experience', is the most fitting, because it calls attention to the subjectivity of conscious mental states. Every phenomenally conscious state, be it a perception, an emotion, a recollection, or (for Husserl and James) a conscious thought $^{13}$ - has a certain subjective character, corresponding to what it is like to live through or undergo that state.

The subjective character of experience, however, needs to be analyzed further. ${ }^{14}$ Phenomenologists are careful to distinguish between 'phenomenality' and 'subjectivity'. Phenomenality corresponds not to qualitative properties of consciousness (qualia), but to the qualitative appearance of the world for consciousness. As Merleau-Ponty puts it, qualia are not elements of consciousness, but qualities for consciousness (1962, p. 5). Subjectivity, on the other hand, corresponds to the first-personal givenness of experience. First-personal givenness can be explained by taking perceptual experience as an example. The object of my perceptual experience — say, the wine bottle on the table - is intersubjectively accessible, in the sense that it can be given to others in the same way it is given to me (from the vantage point of my seat at the table, in this lighting, as half full, and so on). My perceptual experience of the bottle, on the other hand, is given directly only to me. We can both perceive one and the same wine bottle, but we each have our own distinct perceptions of it, and we cannot share these perceptions. In the same sense, we cannot share each other's thoughts, emotions, memories, pains, and so on. A more precise way to formulate this point is to say that you have no access to the first-personal

\footnotetext{
${ }^{13}$ See Zahavi (2004) for discussion of Husserl's view that conscious thoughts, including abstract beliefs, have a phenomenal quality or subjective experiential character.

${ }^{14}$ The next two paragraphs and note 15 draw from Thompson and Zahavi (in press). See also Zahavi (2004).
} 
givenness of my experience, and I have no access to the first-personal givenness of yours. ${ }^{15}$

This notion of first-personal givenness is closely related to the concept of prereflective self-consciousness. When one is directly and non-inferentially aware of one's occurrent thoughts, perceptions, and feelings, they are characterized by a first-personal givenness that immediately reveals them as one's own. This first-personal givenness is not something the experiences could lack while still being experiences. In other words, it is a necessary or essential feature of their being experiences at all. It is their first-personal givenness that makes the experiences subjective. To put it differently, first-personal givenness entails a built-in self-reference, a primitive, experiential self-referentiality.

${ }^{15}$ One might object that this formulation misleadingly suggests that experiences can be given in more than one way, that is, from a perspective other than the first-person perspective. The objection is that either an experience is given from a first-person perspective or it is not given at all (and hence is not an experience). The phenomenological reply, however, is that although any experience must always be given from a firstperson perspective (otherwise it is not an experience), it can also be given from a second-person perspective in empathy. To deny this claim commits one to the view that we never experience the thoughts and feelings of another person in any sense, but can only infer their existence from physical behaviour. This view involves a highly problematic dichotomy between inner experience and outer behaviour. In face-toface encounters, we are confronted neither with a mere physical body, not with a hidden psyche, but with a unified intentional whole. An account of subjectivity and intersubjectivity must start from a correct understanding of the relation between mind and body. Experiences are not internal in the sense of being hidden inside the head (or anywhere else); they express and manifest themselves in bodily gestures and actions. When one sees the face of another person, one sees it as friendly or angry, happy or sad, and so on-it is the very face that expresses these emotions. Moreover, bodily behaviour in general is meaningful and intentionally related to the world, and intentional relations cannot be reduced to inside-outside relations. There simply is no clear sense in which behaviour is external and perceptually available, and experience internal and perceptually inaccessible. These considerations imply that a proper account of subjectivity and intersubjectivity must be based on understanding that the body of the other is fundamentally different from a mere material object, and that our perception of the other's bodily presence is accordingly unlike our perception of material objects. The other is given in its bodily presence as a lived body according to a distinctive form of intentional experience phenomenologists call empathy. In empathy the experiences of another person are given from a second-person perspective and have second-person givenness. Empathy allows us to experience the feelings, desires, and beliefs of others in a more-or-less direct manner. It constitutes a unique form of intentionality, alongside other forms, such as perception, recollection, and imagination. 
When I am aware of an occurrent thought, perception, or feeling from the first-person perspective, the experience is given immediately and non-inferentially as mine. I do not first scrutinize the experience and then identify it as mine. Accordingly, self-awareness cannot be equated with reflective (explicit, thematic, introspective) self-awareness, as some philosophers and cognitive scientists have claimed. Not only is reflective selfawareness only one type of self-awareness, it also presupposes a pre-reflective (implicit, tacit) self-awareness. Self-awareness does not happen only when one realizes reflectively or introspectively that one is perceiving, feeling, or thinking something. Rather, it is legitimate to speak of a primitive but basic type of self-awareness whenever one is acquainted with an experience from a first-person perspective. For an experience to be given in a first-personal mode of presentation to me is for it to be given (at least tacitly) as my experience. For an experience to be given as my experience is for me to be aware of it (at least tacitly) as mine. For me to be aware of it as mine is for me to be self-aware. To be aware of oneself is thus not to apprehend a self apart from experience, but to be acquainted with an experience in its first-personal mode of presentation, as it were from 'within'. The subject or self at issue here is not something standing opposed to, apart from, or beyond experience, nor is it some homuncular entity within experience; it is rather a feature or function of the givenness of experience. In short, the first-personal givenness of experience constitutes the most basic form of selfhood (see Zahavi and Parnas 1998; Zahavi 1999).

In summary, any object-directed, transitive conscious experience, in addition to being of or about its intentional object, is pre-reflectively and intransitively manifest to itself, in virtue of its first-personal givenness. Such self-manifesting awareness is a primitive form of self-consciousness in the sense that (i) it does not require any subsequent act of reflection or introspection, but occurs simultaneously with awareness of the object; (ii) does not consist in forming a belief or making a judgement; and (iii) is passive in the sense of being spontaneous and involuntary.

This conception of pre-reflective self-consciousness can be linked to the correlational structure of intentionality, discussed above (the act/object or noesis/noema structure). Experience involves not simply awareness of its object (noema), but tacit awareness of itself as process (noesis). In consciously seeing an object, one is at the same 
time tacitly and pre-reflectively aware of one's seeing. In visualizing a mental image, one is at the same time tacitly and pre-reflectively aware of one's visualizing. This tacit selfawareness has often been explicated by phenomenologists (most notably Merleau-Ponty) as involving a form of non-objective bodily self-awareness, an awareness of one's lived body or embodied subjectivity, correlative to experience of the intentional object (Merleau-Ponty 1962; Wider 1997; Zahavi 2002). The roots of such pre-reflective bodily self-awareness sink to the involuntary and pre-cognitive level of operative intentionality, the dynamic interplay of affection and receptivity, discussed earlier.

Phenomenology thus converges with certain proposals about 'primary affective consciousness' or 'core consciousness' coming from affective neuroscience (Panksepp 1998b; Damasio 1999). As Parvizi and Damasio state, neuroscience needs to explain both "how the brain engenders the mental patterns we experience as the images of an object" (the noema), and "how, in parallel... the brain also creates a sense of self in the act of knowing... how each of us has a sense of 'me'... how we sense that the images in our minds are shaped in our particular perspective and belong to our individual organism" (Parvizi and Damasio 2001, pp. 136-137). In phenomenological terms, this second issue concerns the noetic aspect of 'ipseity' or the intransitive sense of I-ness in experience. As a number of neuroscientists have emphasized, this core of self-awareness is grounded on bodily processes of life-regulation, emotion, and affect, such that cognition and intentional action are emotive (Damasio 1999; Panksepp 1998a, 1998b; Watt 1999; Freeman 2000), a theme central also to phenomenology (Merleau-Ponty 1962; Jonas 1966; Husserl 2001).

\section{Phenomenal Consciousness and Access Consciousness Revisited}

Let us return now to the distinction between phenomenal consciousness and access consciousness. How does this distinction look from the phenomenological perspective just sketched?

It may be helpful to anchor this discussion in an example. Block (1997, pp. 386387) gives the example of being engaged in an intense conversation while a power drill rattles away outside the window. Engrossed in the conversation, one does not notice the noise, but then eventually and all of sudden one does notice it. Block's proposal is that, 
insofar as one is aware of the noise all along, one is phenomenally conscious of it, but not access conscious of it. When one notices the noise, one becomes access conscious of it (and perhaps also realizes that one has been hearing it all along), so that one now has both phenomenal consciousness and access consciousness of the noise.

O’Regan and Noë (2001, p. 964) dispute this description, claiming that one does not hear the drill until one notices it. One's auditory system may respond selectively to the noise, but one makes no use of the information provided thereby, nor is one poised to make any use of that information, until one notices the drill. Hence there is no ground for thinking we have a case of phenomenal consciousness without access consciousness. In the absence of access, there is no phenomenal consciousness.

From a phenomenological point of view, both descriptions seem somewhat flat. First of all, the phenomenological difference between not noticing and then noticing a noise is treated statically, as if it were a discrete state transition, with no extended temporal dynamics. Secondly, there is no differentiation, either at a static conceptual level or within the temporal dynamics of the experience, between pre-reflective and reflective aspects. One may notice a noise in a pre-reflective or unreflective sense, in which case one inattentively experiences the noise without positing it as a distinct object of awareness. ${ }^{16}$ One may also notice a noise in the sense of turning one's attention to it or having one's attention be captured by it, in which case it does become posited as a distinct object of awareness. Finally, at a pre-reflective level, there is no differentiation between moments of comparatively weak and strong affective force on the part of the noise as the experience unfolds. ${ }^{17}$

\footnotetext{
${ }^{16} \mathrm{O}$ 'Regan and Noë might deny this claim, because they argue that all consciousness is transitive consciousness, and all transitive consciousness is fully attentional: to be conscious of $\mathrm{X}$ is to put all one's sensorimotor and attentional resources onto $\mathrm{X}$, that is, to be "actively probing" $\mathrm{X}$. Besides neglecting intransitive and pre-reflective self-consciousness, this account leaves out the moment of passive affection prerequisite to active probing, and thereby leaves attention unmotivated: what could motivate attention to the sound other than its affecting one inattentively? For further discussion see Thompson (forthcoming). See also Ellis (2001).

${ }^{17}$ Compare Husserl's description of this sort of case: "a soft noise becoming louder and louder takes on a growing affectivity in this materially relevant transformation; the vivacity of it in consciousness increases. This means that it exercises a growing pull on the ego. The ego finally turns toward it. However, examining
} 
These considerations suggest that Block is right that hearing the sound before noticing it is a case of phenomenal consciousness. Yet there seems no good reason to believe that it is a case of phenomenal consciousness without access consciousness (which is the burden of Block's argument). One does consciously hear the sound before noticing it, if 'noticing' means turning one's attention to it. The sound is experienced prereflectively or unreflectively. One lives through the state of being affected by the sound without thematizing the sound or one's affectedness by it. This unreflective consciousness counts as phenomenal consciousness, because the phenomenality (appearance) of the sound has a subjective character, and the sound's affective influence is given first-personally. Hence it does not seem right to say that one has no experience of the sound at all until one notices it (at least if 'notice' means focal attention to the sound). Nevertheless, no compelling reason has been given to believe that this experience is not also a case of access consciousness. After all, one is poised to make use of one's inattentive and unreflective hearing of the sound. Thus the content of pre-reflective experience is at least accessible, even if it is not accessed explicitly. Jennifer Church makes a similar point: "the accessibility (i.e., the access potential) of the hearing experience is evident from the fact that I do eventually access it. Further, it seems that I would have accessed it sooner had it been a matter of greater importance-and thus, in a

this more precisely, the modal transformation of affection has already occurred prior to the turning toward. Along with a certain strength that is at work under the given affective circumstances, the pull proceeding from the noise has so genuinely struck the ego that it has come into relief for the ego, even if only in the antechamber of the ego. The ego already detects it now in its particularity even though it does not yet pay attention to it by grasping it in an attentive manner. This 'already detecting' means that in the ego a positive tendency is awakened to turn toward the object, its 'interest' is aroused-it becomes an acutely active interest in and through the turning toward in which this positive tendency, which goes from the ego-pole toward the noise, is fulfilled in the striving-toward. Now we understand the essential modal transformation that has occurred here. First an increasing affection; but the affective pull is not yet, from the standpoint of the ego, a counter-pull, not yet a responsive tendency toward the allure issuing from the object, a tendency that for its part can assume the new mode of an attentively grasping tendency. There are further distinctions that can be made here, but they do not concern us at this time" (Husserl 2001, p. 215). This description is explicitly temporal and dynamic; it displays phenomenal consciousness as characterized by continuous graded transformations of accessibility or access potential; and it roots modal transformations of consciousness in the dynamics of affect and movement tendencies (emotion). 
still stronger sense, it was accessible all along. Finally, it is not even clear that it was not actually accessed all along insofar as it rationally guided my behaviour in causing me to speak louder, or move closer, and so forth" (Church 1997, p. 426). On the other hand, if we imagine that one is not cognitively poised in any way to rely on the sound, then we would need a reason to believe that one is nonetheless phenomenally conscious of it, rather than simply discriminating (differentially responding to) it nonconsciously, but no reason is forthcoming simply from this example.

The terminology of 'access consciousness' and 'phenomenal consciousness' is foreign to traditional phenomenology, and so it would be problematic to use this distinction to explicate phenomenological ideas. On the one hand, phenomenologists emphasize that most of experience is lived through unreflectively and inattentively, with only a small portion being thematically or attentively given. This view differentiates phenomenology from views that identify the contents of consciousness strictly with the contents of focal attention. On the other hand, as far as we can see, phenomenological analyses provide no reason to think that at this unreflective, implicit level it is conceptually possible for there to be experiences that are not accessed by or accessible to other mental states and processes guiding behaviour.

In summary, according to phenomenology, lived experience comprises prereflective, pre-cognitive, and affectively valenced mental states. These states are subjectively lived through, and thus have an experiential or phenomenal character, but their contents are not thematized. These states are also necessarily states of pre-reflective self-awareness (they have first-personal givenness), otherwise they do not qualify as conscious at all. Although not explicitly accessed in focal attention, reflection, introspection, and verbal report, they are accessible in principle: they are the kind of states that can become available to attention, reflection, introspection, and verbal report. In order to make active use of this potential access, however, first-person/second-person methods of phenomenological attentiveness and explication may be required. Thus whereas many theorists discuss access consciousness and phenomenal consciousness in largely static terms, a phenomenological approach would reorient the theoretical framework by emphasizing the dynamics of the whole intentional structure of consciousness (the noetic-noematic structure), in particular the structural and temporal 
dynamics of becoming aware at pre-reflective and reflective levels. Of particular concern to neurophenomenology is the process whereby implicit, unthematized, and intransitively lived through aspects of experience can become thematized and verbally described, and thereby made available in the form of intersubjective, first-person data for neuroscientific research on consciousness. The rationale for introducing first-person methods into affective-cognitive neuroscience is to facilitate this process (see Section 6).

5. Neurodynamics and Large-Scale Integration

As we mentioned in Section 2, from an enactive perspective, the endogenous, selforganizing dynamics of large-scale neural activity is the appropriate level for characterizing neural processes in relation to mental activity. Neuroscience leaves little doubt that specific cognitive acts (such as visual recognition of a face) require the transient integration of widely distributed and continually interacting brain areas. It is also widely accepted that the neural activity crucial for consciousness involves the transient and continual orchestration of scattered mosaics of functionally specialized brain regions, rather than any single brain process or structure. Hence a common theoretical proposal is that each moment of conscious awareness involves the transient selection of a distributed neural population that is both integrated or coherent, and differentiated or flexible, and whose members are connected by reciprocal and transient dynamic links. ${ }^{18}$ A prelude to understanding the neural processes crucial for consciousness is to identify the mechanisms and dynamic principles of this large-scale activity. This problem is known as the large-scale integration problem (Varela, Lachaux. Rodriguez, and Martinerie 2001). Large-scale brain processes typically display endogenous, self-organizing behaviours, which are highly variable both from trial to trial and across subjects, and cannot be fully controlled by the experimentalist. Hence affective-cognitive neuroscience faces at least a twofold challenge: (i) to find an adequate conceptual framework to understand brain complexity, and (ii) to relate brain complexity to conscious experience in an epistemologically and methodologically rigorous way.

\footnotetext{
${ }^{18}$ See Varela (1995), Tononi and Edelman (1998), Freeman (1999a, 1999b), Dehaene and Naccache (2001), Engel and Singer (2001), Thompson and Varela (2001), Crick and Koch (2003).
} 


\section{Brain Complexity}

For the first challenge, neurophenomenology follows the strategy, now shared by many researchers, of using the framework of complex dynamic systems theory. (This strategy corresponds to NPh2 above.) According to the dynamical framework, the key variable for understanding large-scale integration is not so much the activity of the system's components, but rather the dynamic nature of the links between them. The neural counterpart of subjective experience is thus best studied not at the level of specialized circuits or classes of neurons (Crick and Koch 1998), but through a collective neural variable that describes the emergence and change of patterns of large-scale integration (Varela, Lachaux, Rodriguez, and Martinerie 2001). One recent approach to defining this collective variable of large-scale integration is to measure transient patterns of phase synchronization and desynchronization between oscillating neural populations at multiple frequency bands (Varela, Lachaux, Rodriguez, and Martinerie 2001; Engel, Fries, and Singer 2001). A number of researchers have hypothesized that such dynamic large-scale integration is involved in or required for certain generic features of consciousness, such as unity (Varela and Thompson 2003), integration and differentiation (Tononi and Edelman 1998), transitoriness and temporal flow (Varela 1995, 1999), and awareness of intentional action (Freeman 1999b).

We can explain the reasoning behind this approach in the form of two working hypotheses (Varela 1995; see also David, Cosmelli, Lachaux, Baillet, Garnero, and Martinerie 2003; Le Van Quyen 2003):

Hypothesis I: For every (type of) cognitive act, there is a singular and specific (type of) large-scale neural assembly that underlies its emergence and operation.

A neural assembly can be defined as a distributed subset of neurons with strong reciprocal connections. In the context of large-scale integration, a neural assembly comprises not only clusters of strongly interacting pyramidal cells and interneurons at a local scale, but also more remote areas actively connected by excitatory pathways. On the one hand, there are reciprocal connections within the same cortical area, or between areas at the same level of the network. On the other hand, there are reciprocal connections that 
link different levels of the network in different brain regions to the same assembly (Varela, Lachaux, Rodriguez, and Martinerie 2001). Because of these strong interconnections (recall the principle of reciprocity mentioned in Section 2), a large-scale neural assembly can be activated or ignited from any of its smaller subsets, whether sensorimotor or internal. These assemblies have a transient, dynamic existence that spans the time required to accomplish an elementary cognitive act (such as visual recognition of a face) and for neural activity to propagate through the assembly. Various empirical, theoretical, and phenomenological considerations suggest that the time-scale of such neurocognitive activity - whether it be a perception/action state, passing thought or memory, or emotional appraisal - is in the range of fractions of a second. ${ }^{19}$ During these successive time intervals, there is competition between different neural assemblies: when a neural assembly is ignited from one or more of its smaller subsets, it either reaches a distributed coherence or is swamped by the competing activations of overlapping neural assemblies. If the assembly holds after its activation, one can assume it has a transitory efficient function. The holding time is bound by two simultaneous constraints: (1) it must be larger than the time for spike transmission either directly or through a small number of synapses (from a few milliseconds to several tens of milliseconds); and (2) it must be smaller than the time it takes for a cognitive act to be completed, which is on the order of several hundreds of milliseconds. Thus the relevant neuronal processes are distributed not only in space, but also over periods of time that cannot be compressed beyond a certain limit (a fraction of a second).

Hypothesis I is a strong one, for it predicts that only one dominant or major neural assembly is present during a cognitive act, and that physiological correlates associated with the assembly should be repeatedly detected for different token realizations of the same act (for instance in an odd-ball discrimination task or go/no-go task in the laboratory). The formation of the dominant assembly involves the selection (incorporation and rejection) of multiple neuronal activities distributed over both cortical and subcortical areas. The total flexible repertoire of such dynamic neural assemblies

\footnotetext{
${ }^{19}$ See Varela, Thompson, and Rosch (1991, pp. 72-79), Dennett and Kinsbourne (1992), Varela (1995, 1999), Lewis (2000), Crick and Koch (2003), VanRullen and Koch (2003).
} 
provides the 'dynamic core' of cognition (Tononi and Edelman 1998; Le Van Quyen 2003).

Given this first hypothesis, the issue arises of how large-scale dynamic integration is actually accomplished in the brain so as to produce a flow of coherent and adaptive cognitive acts. The basic intuition is that a specific neural assembly arises through a kind of 'temporal glue'. The most well studied candidate for this temporal integrative mechanism is neural phase synchronization. Neuronal groups exhibit a wide range of oscillations, from theta to gamma ranges (spanning 4-80 hertz or cycles a second), and can enter into precise synchrony or phase-locking over a limited period of time (a fraction of a second). ${ }^{20}$ A growing body of evidence suggests that synchronization on a millisecond time-scale serves as a mechanism of brain integration (Varela, Lachaux, Rodriguez, and Martinerie 2001; Engel, Fries, and Singer 2001). This idea can be stated in the form of a second hypothesis (Varela 1995):

Hypothesis II: A specific neural assembly is selected through the fast, transient phase-locking of activated neurons belonging to sub-threshold competing neural assemblies.

Neural phase synchrony is a multiscale phenomenon occurring in local, regional, and long-range networks. It is useful to distinguish between two main scales, short-range and long-range. Short-range integration occurs over a local network (e.g., columns in

\footnotetext{
${ }^{20}$ Synchrony in this context refers to the relation between the temporal structures of the signals regardless of signal amplitude. Two signals are said to be synchronous if their rhythms coincide. In signals with a dominant oscillatory mode, synchronization means the adjustment of the rhythmicity of two oscillators in a phase locking:

$$
n \phi_{1}(t)-m \phi_{2}(t)=\text { const }
$$

where $\phi_{1}(\mathrm{t}), \phi_{2}(\mathrm{t})$ are the instantaneous phases of the oscillators, and $n, m$ are integers indicating the ratios of possible frequency locking. It is usually assumed for simplicity that $n=m=1$, but evidence for $1: 2$ and 1:3 phase synchrony also exists (see Lachaux, Rodriguez, Martinerie, and Varela 1999; Varela, Lachaux, Rodriguez, and Martinerie 2001; Le Van Quyen 2003).
} 
primary visual cortex), distributed over an area of approximately 1 centimeter, through monosynaptic connections with conduction delays of 4 to 6 milliseconds. Most electrophysiological studies in animals have dealt with short-range synchronies or synchronies between adjacent areas corresponding to a single sensory modality. These local synchronies have usually been interpreted as a mechanism of "perceptual binding' - the selection and integration of perceptual features in a given sensory modality (e.g., visual Gestalt features) (Singer 1999). Large-scale integration concerns neural assemblies that are farther apart in the brain, and connected through polysynaptic pathways with transmission delays greater than 8 to 10 milliseconds (for a review see Varela, Lachaux, Rodriguez, and Martinerie 2001). In this case, phase synchrony cannot be based on the local cellular architecture, but must instead reside in distant connections (cortico-cortical fibers or thalamocortical reciprocal pathways). These pathways correspond to the large-scale connections that link different levels of the network in different brain regions to the same assembly.

Long-distance phase synchronization is hypothesized to be a mechanism for the transient formation of a coherent macro-assembly that selects and binds multimodal networks (such as assemblies between occipital and frontal lobes, or across hemispheres, which are separated by dozens of milliseconds in transmission time). Phase synchrony measures have predictive power with respect to subsequent neural, perceptual, and behavioural events (Engel, Fries, and Singer 2001). Animal and human studies demonstrate that specific changes in synchrony occur during arousal, sensorimotor integration, attentional selection, perception, and working memory, all of which are crucial for consciousness (for reviews see Engel, Fries, and Singer 2001; Varela, Lachaux, Martinerie and Rodriguez 2001). It has also been hypothesized that whether a local process participates directly in a given conscious state depends on whether it participates in a coherent, synchronous global assembly (Dehaene and Naccache 2001; Engel and Singer 2001). Evidence for these hypotheses comes from studies at coarser levels of resolution than the microscale of single neuron activity, namely, the intermediate or mesoscale of local field potentials (the summated dendritic current of local neural groups), and the macroscale of scalp recordings in EEG (electroencephalography) and MEG (magnetoencephalography). These studies provide 
direct evidence for long-range synchronizations between widely separated brain regions during cognitive tasks.

Long-distance phase synchronies occur in a broad range of frequencies. Fast rhythms (above 15 hertz) in gamma and beta frequencies meet the requirement for fast neural integration, and thus are thought to play a role in conscious processes on the time scale of fractions of a second (Varela 1995; Tononi and Edelman 1998). Yet neural synchrony must also be understood in the context of the slower alpha and theta bands (412 hertz), which play an important role in attention and working memory (Sarnthein, Petsche, Rappelsberger, Shaw, and von Stein 1998; von Stein, Chiang, and König 2000; von Stein and Sarnthein 2000; Fries, Reynolds, Rorie, and Desimone 2001), sensorimotor integration (O’Keefe and Burgess 1999; Kahana, Seelig, and Madsen 2001), and probably emotion (Lewis in press). This evidence supports the general notion that phase synchronization subserves not simply the binding of sensory attributes, but the overall integration of all dimensions of a cognitive act, including associative memory, affective tone and emotional appraisal, and motor planning (Damasio 1990; Varela 1995; Varela, Lachaux, Rodriguez, and Martinerie 2001). More complex nonlinear forms of cross-band synchronization, so-called 'generalized synchrony' (Schiff, So, Chang, Burke, and Sauer 1996), are thus also expected, and may indeed prove more relevant in the long run to understanding large-scale integration than strict phase synchronization (Friston 2000a, 2000b; Varela, Lachaux, Rodriguez, and Martinerie 2001; Le Van Quyen 2003).

It should be emphasized that large-scale integration must involve not only the establishment of dynamic links, but also their active uncoupling or dismantling, in order to make way for the next cognitive moment. Thus not only phase synchronization but also desynchronization or phase scattering is likely to play an important role in largescale integration (Varela 1995; Rodriguez, George, Lachaux, Martinerie, Renault, and Varela 1999; Varela, Lachaux, Rodriguez, and Varela 2001, p. 236). A dynamic of synchronization and desynchronization, combined with retention or hold-over of elements from the previous assembly at the beginning of each new one, might be the neural basis for the apparent unity and moment-to-moment transitoriness in the temporal flow of experience (Varela 1999). 
In summary, Hypotheses I and II taken together imply that a succession of cognitive events is correlated to a succession of bursts of phase synchronization and desynchronization between either remote or close neural signals in large-scale neural assemblies. The neurophenomenological approach to brain complexity involves testing these working hypotheses, as well as developing new dynamic systems techniques for investigating more complex forms of cross-band relations (Lachaux, Chavez, and Lutz 2003; David, Cosmelli, and Friston 2004).

\section{Relating Brain Complexity to Experience: Varela's 'Core Hypothesis'}

The second challenge mentioned above is to relate brain complexity to conscious experience in a rigorous way. Let us address this point first at a theoretical level, and then at a methodological level.

At a theoretical level, a working hypothesis is needed to specify explicitly what the link between conscious experience and large-scale integration via synchrony is supposed to be. An early hypothesis about this relation was proposed by Varela (1995). His idea was that the large-scale neural assembly that dominates over competing subthreshold assemblies constitutes a transient self-referential pole for the interpretation of current neural activity, and that conscious mental states are in effect neural interpretations of neural events. Similar proposals have since been put forward by Tononi and Edelman (1998), and recently by Crick and Koch (2003). Varela's version takes the form of rephrasing Hypotheses I and II in the following 'core hypothesis':

Core Hypothesis: Mental-cognitive states are interpretations of current neural activity, carried out in reference to a transient, coherency-generating process generated by that nervous system.

We cite here Varela's original formulation (Varela 1995, pp. 90-91). A clearer rendering of what he means would be: a mental-cognitive state is a neural interpretation of current neural activity, carried out by and in reference to a transient and coherent large-scale assembly, generated by the nervous system of an embodied and situated agent. 
The mental-cognitive states of concern in this discussion are conscious mental states. A conscious mental state is one having a subjective or first-personal character. Its content involves an appearance of something to someone (it is phenomenal and subjective). The issue is how to relate phenomenal content and subjectivity to neural processes on the microtemporal scale of a fraction of a second. Damasio has noted that many neurobiological proposals about consciousness focus on the problem of the specific phenomenal (e.g., sensory) contents of consciousness, while neglecting the problem of subjectivity or selfhood, "the problem of how, in parallel with engendering mental patterns for an object, the brain also engenders a sense of self in the act of knowing” (Damasio 1999, p. 9). Varela's core hypothesis tries to keep both aspects together. On the one hand, the specific contents of current neural events derive from the organism's sensorimotor coupling and from the endogenous activity of its nervous system. On the other hand, these distributed and local neural events are always being evaluated from the point of view of the large-scale assembly dominant at the moment. This assembly acts as a global and dynamic self-referential pole - a sort of transient virtual self-for the selection of local activity. $^{21}$

To say that a mental-cognitive state is a neural 'interpretation' of current neural activity means that distributed and local neural events are never taken at face value, but are always 'seen' or 'evaluated' from the point of view of the assembly most dominant at the time. For example, a specific mental-cognitive act, such as visual recognition of a face, will be lived differently depending on factors such as arousal, motivation, attention, and associative memories unique to the individual. The neural events specific to the recognition will not be taken at face value, but will be shaped and modified by the dominant large-scale assembly integrating frontal and limbic activities. Such endogenous large-scale activity is always present and forms a global background for evaluating local events generated exogenously and endogenously (see also Freeman 2000). On the other hand, these local events modulate and contribute to the emergence of a dominant assembly from competing sub-threshold assemblies. This circular causality sustains a

\footnotetext{
${ }^{21}$ Of course this transient pole of integration must be embedded in the brainstem and body-regulation processes constitutive of the proto-self (dynamic neural patterns that map the body state) and core consciousness (primitive self-consciousness) (see Parvizi and Damasio 2001).
} 
kind of 'neural hermeneutics' or 'neural hermeneutical circle', in which a pre-existing dominant assembly (a background pre-understanding) shapes the meaning of novel events (motivates an interpretation), while being modified by those events (the interpretation leads to a new understanding). For instance, as we will see below when looking at some experimental work, the visual recognition of an image is experienced differently depending on the subjective context leading up to the moment of perception, and these differences in antecedent subjective context and subsequent perception are reflected in corresponding differences in the local and long-distance patterns of phasesynchronization and desynchronization in large-scale assemblies (Lutz, Lachaux, Martinerie, and Varela 2002).

According to the core hypothesis, the large-scale neurodynamics of mental states should exhibit three generic characteristics (Le Van Quyen 2003): (1) metastability: the coherence-generating process constantly gives rise to new large-scale patterns without settling down or becoming trapped in any one of them (Kelso 1995; Friston 2000a, 2000b); (2) rapid integration: these patterns are generated quickly, on a time period of 100 to 300 milliseconds; and (3) a global self-reference pole: the coherence-generating process provides a global self-referential pole for the selection (incorporation and rejection) of ongoing local neuronal activities. The inevitable multiplicity of concurrent potential assemblies is evaluated in relation to this dynamic reference pole, until one assembly is transiently stabilized and expressed behaviorally, before bifurcation to another. A map of conceptual and mathematical frameworks to analyze these spatiotemporal large-scale brain phenomena has recently been proposed by Le Van Quyen (2003).

The core hypothesis is not meant to be an a priori internalist identity thesis of either a type-type $($ mental properties $=$ neural properties $)$ or token-token (mental events $=$ neural events) form. It is meant rather as an empirical hypothesis about how to distinguish in the brain the neural events underlying or directly contributing to a distinct mental state (on a fraction-of-a-second time scale) from other neural events going on in the nervous system. Nor is there any suggestion that the former sort of distinctly neurocognitive events is sufficient for mental states. According to the hypothesis, every mental state (or cognitive act) requires the formation of a specific large-scale neural 
assembly. It does not follow, however, that the internal neural characteristics of such assemblies are sufficient for their correlative mental states. On the contrary, the somatic and dynamic sensorimotor context of neural activity is also crucial (Thompson and Varela 2001; Hurley and Noë 2003; Noë and Thompson 2004a, 2004b). According to the enactive approach, mental states depend crucially on the manner in which neural processes are embedded in the somatic and environmental context of the organism's life, and hence it is doubtful that there is such a thing as a minimal internal neural correlate, even a complex dynamical one, whose intrinsic properties are sufficient for conscious experience.

Finally, the transient, coherence-generating process referred to in the core hypothesis is hypothesized to be none other than large-scale integration via phasesynchronization (a mechanism that will probably have to be expanded to include generalized synchrony). Thus, among the various ways to define the state variable of large-scale coherence, one recent approach is to use as a 'dynamical neural signature' the description and quantification of transient patterns of local and long-distance phase synchronies occurring between oscillating neural populations at multiple frequency bands (Rodriguez, George, Lachaux, Martinerie, Renault, and Varela 1999; Lutz, Lachaux, Martinerie, and Varela 2002; Cosmelli, David, Lachaux, Martinerie, Garnero, Renault, and Varela, submitted). (This proposal corresponds to a specific working hypothesis under the heading of NPh3 above.) Current neurophenomenology thus assumes that local and long-distance phase synchrony patterns provide a plausible neural signature of subjective experience.

\section{Relating Brain Complexity to Conscious Experience: Methodology}

At a methodological level, neurophenomenology's new and original proposal is to test the core hypothesis by incorporating careful phenomenological investigations of experience into neurodynamical studies in an explicit and rigorous way. The aim is to integrate the phenomenal structure of subjective experience into the real-time characterization of large-scale neural activity. The response to the second challenge of relating brain complexity to conscious experience is accordingly to create experimental situations in which the subject is actively involved in identifying and describing 
phenomenal categories and structural invariants of experience that can be used to identify and describe dynamical neural signatures of experience and structural invariants of brain activity. As we will see below (Section 7), a rigorous relationship between brain complexity and subjective experience is thereby established, because original phenomenal categories and structural invariants are explicitly used to detect original neurodynamical patterns. Such joint collection and analysis of first-person and thirdperson data instantiates methodologically the neurophenomenological hypothesis that neuroscience and phenomenology can be related to each other through reciprocal constraints (Varela 1996). The long-term aim is to produce phenomenological accounts of real-time subjective experience that are sufficiently precise and complete to be both expressed in formal and predictive dynamical terms, and shown to be realized in specific neurodynamical properties of brain activity. Such threefold, phenomenological, formal, and neurobiological descriptions of consciousness could provide a robust and predictive way to link reciprocally the experiential and neurophysiological domains.

\section{First-Person Methods}

For this approach to move forward, better methods for obtaining phenomenological data are needed. The role of first-person methods is to meet this need. First-person methods are disciplined practices subjects can use to increase their sensitivity to their experience from moment to moment (Varela and Shear 1999a). They involve systematic training of attention and emotional self-regulation. Such methods exist in phenomenology (Moustakas 1994; Depraz 1999), psychology (Price and Barrell 1980; Price, Barrell, and Rainville 2002), psychotherapy (Gendlin 1981; Epstein 1996), and contemplative meditative traditions (Varela, Thompson, and Rosch 1991; Wallace 1999). Some are routinely used in clinical and health programs (Kabat-Zinn 1990), and physiological correlates and effects of some of these practices have been investigated (Austin 1998; Davidson, Kabat-Zinn, Schumacher, Rosenkranz, Muller, Santorelli, Urbanowski, Harrington, Bonus, and Sheridan 2003). The relevance of these practices to neurophenomenology derives from the capacity for sustained awareness of experience they systematically cultivate. This capacity enables tacit, pre-verbal, and pre-reflective aspects of subjective experience - which otherwise would remain unreflectively lived 
through — to become subjectively accessible and describable, and thus available for intersubjective and objective (biobehavioural) characterization.

First-person methods vary depending on the phenomenological, psychological, or contemplative framework. The following schema, taken from Varela and Shear (1999b, p. 11), calls attention to certain generic features of first-person methods:

- Basic attitude: suspension (of inattentive immersion in the content of experience), redirection (of awareness to ongoing process of experience), and receptive openness (to newly arising experience). This stance or posture must be adopted in one's own first-person singular case.

- Intuitive filling-in: stabilizing and sustaining the basic attitude so that awareness of the experiencing process becomes fuller in content. This process requires practice, and involves the second-person perspective of a trainer or coach.

- Expression and intersubjective validation: this step of verbal description and intersubjective evaluation is required in order for there to be any valid first-person (phenomenological) data. It implicates and is always situated in a first-person plural perspective.

In phenomenology, the basic attitude of suspension, redirection, and receptive openness is known as the 'epoché'. This term originally comes from Greek skepticism, where it means to refrain from judgement, but Husserl adopted it as a term for the suspension, neutralization, or bracketing of our naïve realistic inclinations about the relationship between the world and our experience. As a procedure carried out in the first-person by the phenomenologist, the epoché is a practiced mental gesture of redirecting one's attention from the intentional object of experience to one's experiencing of the object, such that the object is now taken strictly as the objective correlate of the experiencing act or process. The basic principle of phenomenological analysis is that analysis of the experiencing process, rather than the specific objects of experience, discloses the invariant structures and factors within and across different types of experience. 
The three phases of suspension, redirection, and receptive openness form a dynamic cycle. The first phase induces a transient suspension of beliefs or habitual thoughts about what is experienced. The aim is to bracket explanatory belief-constructs in order to adopt an open and unprejudiced descriptive attitude. This attitude is an important prerequisite for gaining access to experience as it is lived pre-reflectively. The second phase of redirection proceeds on this basis: given an attitude of suspension, one's attention can be redirected from its habitual immersion in the object toward the lived character of the experiencing process. The epoché thus mobilizes and intensifies the tacit self-awareness of experience by inducing an explicit attitude of bare attention to the experiencing process. 'Bare attention' means noticing, witnessing, or being present to what is happening in one's experience, without explanation or judgement. This requires acceptance of whatever is happening, or in other words a receptive openness. Thus an attitude of receptivity or letting-go is encouraged, in order to broaden the field of experience to new horizons. Many aspects of experience are not noticed immediately, but require multiple instances and variations in order to emerge. The repetition of the same task in an experimental setting, for instance, enables new contrasts to arise, and validates emerging phenomenal categories and structural invariants. Training and practice are therefore a necessary component to cultivate all three phases, and to enable the emergence and stabilization of phenomenal invariants.

Downstream from this threefold cycle is the phase of verbalization or expression. The communication of phenomenal invariants provides the crucial step whereby this sort of first-person knowledge can be intersubjectively shared and calibrated, and eventually related to objective data.

This account of the procedural steps of the epoché represents an attempt to fill a lacuna of phenomenology, which has emphasized theoretical analysis and description, to the neglect of the actual pragmatics of the epoché (Depraz 1999). By contrast, the pragmatics of 'mindfulness' in the Buddhist tradition is far more developed (Varela, Thompson, and Rosch 1991). This is one reason that the above description of the structural dynamics of becoming aware, as well as attempts to develop a more pragmatic phenomenology, have drawn from Buddhist traditions of mental discipline (Varela, Thompson, and Rosch 1991; Depraz, Varela, and Vermersch. 2000, 2003). One can also 
point to a recent convergence of theories and research involving introspection (Vermersch 1999), the study of expertise and intuitive experience (Petitmengin-Peugeot 1999; Petitmengin 2001), phenomenology (Depraz 1999), and contemplative mental selfcultivation (Wallace 1999). This convergence has also motivated and shaped the above description of the generic features of first-person methods (see Depraz, Varela, and Vermersch 2000, 2003).

The use of first-person methods in affective-cognitive neuroscience clearly raises important methodological issues. One needs to guard against the risk of the experimentalist either biasing the phenomenological categorization or uncritically accepting it. Dennett (1991) introduced his method of 'heterophenomenology' (phenomenology from a neutral third-person perspective) in part as a way of guarding against these risks. His warnings are well taken. Neurophenomenology asserts that firstperson methods are necessary to gather refined first-person data, but not that subjects are infallible about their own mental lives, nor that the experimentalist cannot maintain an attitude of critical neutrality. First-person methods do not confer infallibility upon subjects who use them, but they do enable subjects to thematize important but otherwise tacit aspects of their experience. At the time of this writing, Dennett has not addressed the issue of the scope and limits of first-person methods from his heterophenomenological viewpoint, so it is not clear where he stands on this issue. A full exchange on this issue would require discussion of the different background epistemological and metaphysical differences between phenomenology and heterophenomenology concerning intentionality and consciousness. There is not space for such a discussion here. ${ }^{22}$ We will therefore restrict ourselves to a comment about heterophenomenology as a method for obtaining first-person reports. Our view is that to the extent that heterophenomenology rejects firstperson methods, it is too limited a method for the science of consciousness, because it is unable to generate refined first-person data. On the other hand, to the extent that heterophenomenology acknowledges the usefulness of first-person methods, then it is

\footnotetext{
${ }^{22}$ For discussion of some aspects of this issue, see Thompson, Noë, and Pessoa (1999). A forthcoming special issue of Phenomenology and the Cognitive Sciences devoted to heterophenomenology will contain a paper by Thompson addressing the relations among heterophenomenology, phenomenology, and neurophenomenology.
} 
hard to see how it could avoid becoming in its practice a form of phenomenology, such that the supposed opposition between 'hetero' and 'auto' phenomenology would no longer apply.

Another issue concerns the way that attention to experience can modify or affect the intentional content and phenomenal character of experience (Lambie and Marcel 2002). First-person methods rely on a sheer witnessing or noticing of the process of experiencing, a bare attention without judgement. Their effect on experience is accordingly different from introspection (in the introspectionist sense), which uses active attention to the objects of experience as its basis (thus the introspectionists used active attention to a sensory stimulus as the basis for introspecting a sensation or image). Bare attention is not intrusive, but maintains a light touch. First-person methods intensify or heighten awareness by mobilizing this kind of nonjudgemental attention.

This last point raises a related issue - the modification of experience by phenomenological training. If first-person methods work to transform awareness from an unstable and inattentive mode to a more stable and attentive one, then it follows that experience is being trained and reshaped. One might therefore object that one mode of experience is replacing another, and hence the new mode of experience cannot be used to provide insight into the earlier mode of untrained experience. Although at a superficial level there may seem to be an incompatibility between gaining insight into something and transforming it, this way of looking at things is misguided. There need not be any inconsistency between altering or transforming experience (in the way envisaged), and gaining insight into experience through such transformation. If there were, then one would have to conclude that no process of cognitive or emotional development could provide insight into experience before the period of such development. Such a view is extreme and unreasonable. The problem with the objection is its assumption that experience is a static given, rather than dynamic, plastic, and developmental. Indeed, it is hard to see how the objection could even be formulated without presupposing that experience is a fixed, predelineated domain, related only externally to the process of becoming aware, such that this process would have to supervene from outside, instead of being motivated and called forth from within experience itself. First-person methods are not supposed to be a way of accessing such a (mythical) domain; they are supposed to be 
a way of enhancing and stabilizing the tacit self-awareness already intrinsic to experience, thereby 'awakening' experience to itself.

It is also to be expected that the stabilization of new phenomenal invariants in experience, resulting from using first-person methods, will be associated with specific short-term or long-term changes in brain activity. It has been shown, for instance, that category formation during learning is accompanied by changes in the ongoing dynamics of the cortical stimulus representation (Ohl, Scheich, and Freeman 2001). But the fact that phenomenological training can modify experience and brain dynamics is not a limitation, but an advantage. Anyone who has acquired a new cognitive skill (such as stereoscopic fusion, wine-tasting, or a second language) can attest that experience is not fixed, but dynamic and plastic. First-person methods help to stabilize phenomenal aspects of this plasticity so that they can be translated into descriptive first-person reports. As Frith writes in a recent comment on introspection and brain imaging: "A major programme for $21^{\text {st }}$ century science will be to discover how an experience can be translated into a report, thus enabling our experiences to be shared" (Frith 2002, p. 374). First-person methods help 'tune' experience, so that such translation and intersubjective corroboration can be made more precise and rigorous. The issue of the generality of data from trained subjects remains open, but seems less critical at this stage of our knowledge than the need to obtain new data about the phenomenological and physiological processes constitutive of the first-person perspective.

Frith (2002), following Jack and Roepstorff (2002), also comments "sharing experiences requires the adoption of a second-person perspective in which a common frame of reference can be negotiated" (p. 374). First-person methods help to establish such a reference frame by incorporating the mediating 'second-person' position of a trainer or coach. Neurophenomenology thus acknowledges the intersubjective perspective involved in the science of consciousness (Thompson 2001; Depraz and Cosmelli 2004). The subject needs to be motivated to cooperate with the experimentalist and empathetically to understand her motivations; and reciprocally the experimentalist needs to facilitate the subject's finding his own phenomenal invariants. Without this reciprocal, empathetically grounded exchange, there is no refined first-person data to be had. 


\section{Experimental Studies}

In this section we review two experimental studies of consciousness and large-scale cortical dynamics. Each study used a visual perception protocol (depth perception and binocular rivalry respectively). In the first study, individual subjects gave detailed trialby-trial accounts of their experience, and these descriptions were used to define stable experiential categories or phenomenal invariants for each individual subject. These phenomenal invariants were then used to detect and interpret neural imaging data (Lutz, Lachaux, Martinerie, and Varela 2002). In the second study, a strict structural invariant of experience for all subjects was defined, and then used as a heuristic to reveal a corresponding structural invariant of cortical dynamics (Cosmelli 2004; David, Cosmelli, Hasboun, Garnero 2003; Cosmelli, David, Lachaux, Martinerie, Garnero, Renault, and Varela, submitted). Both studies were explicitly motivated by the methodology and hypotheses of the neurophenomenological approach.

\section{The Subjective Context of Perception}

When an awake and alert subject is stimulated during an experiment, his brain is not idle or in a state of suspension, but is engaged in cognitive activity. The brain response derives from the interaction between this ongoing activity and the afferent stimulation that affects it. Yet because this ongoing activity has not been carefully studied, most of the brain response is not understood: successive exposure to the same stimulus elicits highly variable responses, and this variability is treated as unintelligible noise (and may be discarded by techniques that average across trials and/or subjects). The source of this variability is thought to reside mainly in fluctuations of the subjective cognitive context, as defined by the subject's attentional state, spontaneous thought processes, strategy to carry out the task, and so on. Although it is common to control, at least indirectly, for some of these subjective factors (such as attention, vigilance, or motivation), the ongoing subjective mental activity has not yet been analyzed systematically.

One strategy would be to describe in more detail this ongoing activity by obtaining verbal reports from human subjects. These reports should reveal subtle changes in the subject's experience, whether from trial to trial, or across individuals. This type of qualitative first-person data is usually omitted from brain-imaging studies, yet if 
methodological precautions are taken in gathering such data, they can be used to shed light on cognition via a joint analysis with quantitative measures of neural activity. Following this approach, a pilot neurophenomenological study (Lutz, Lachaux, Martinerie, and Varela 2002) investigated variations in subjective experience for one limited aspect of visual perception, namely, the emergence of an illusory 3D figure during the perceptual fusion of 2D random-dot images with binocular disparities.

The task began with subjects fixating for seven seconds a dot pattern containing no depth cues. At the end of this 'preparation period', the pattern was changed to a slightly different one with binocular disparities. Subjects then had to press a button as soon as the 3D shape had completely emerged. Throughout the trial dense-array EEG signals were recorded, and immediately after the button-press subjects gave a brief verbal report of their experience. In these reports, they labeled their experience using phenomenal categories or invariants that they themselves had found and stabilized during a prior training session. The recording-session thus involved the simultaneous collection of first-person data (phenomenological reports) and third-person data (electrophysiological recordings and behavioural measures of button-pressing reaction time).

In the training session, subjects intensively practiced performing the task in order to improve their perceptual discrimination and to enable them to explore carefully variations in their subjective experience during repeated exposure to the task. Subjects were instructed to direct their attention to their own immediate mental processes during the task and to the felt-quality of the emergence of the 3D image.

This redirection of awareness to the lived quality of experience corresponds to the epoché described in the previous section. Its aim is to intensify the tacit self-awareness of experience by inducing a more explicit awareness of the experiencing process correlated to a given experiential content. More simply put, the aim is to induce awareness not simply of the 'what' or object-pole of experience (the 3D percept), but also of the necessarily correlated 'how' or act-pole of experience (the performance of perceptual fusion and its lived or subjective character). As described above, this practice of becoming aware involves the three interlocking phases of suspension, redirection, and receptive openness. 
In this pilot study, these phases were either self-induced by subjects familiar with them, or facilitated by the experimenter through open questions (Petitmengin-Peugeot 1999). For example: Experimenter, "What did you feel before and after the image appeared?" Subject, "I had a growing sense of expectation but not for a specific object; however, when the figure appeared, I had a feeling of confirmation, no surprise at all." Or, "It was as if the image appeared in the periphery of my attention, but then my attention was suddenly swallowed up by the shape."

Subjects were repeatedly exposed to the stimuli, and trial by trial they described their experience through verbal accounts, which were recorded on tape. In dialogue with the experimenters, they defined their own stable experiential categories or phenomenal invariants to describe the main elements of the subjective context in which they perceived the 3D shapes. The descriptive verbal reports from a total of four subjects were classified according to the common factor of degree of preparation felt by the subject and quality of perception. This factor was used to cluster the trials into three main categories, described below: Steady Readiness, Fragmented Readiness, and Unreadiness. Subcategories (describing the unfolding of the visual perception, for instance) were also found in individual subjects. These were not investigated in the pilot study.

- Steady Readiness. In most trials, subjects reported that they were "ready," "present," "here," or "well-prepared" when the image appeared on the screen, and that they responded "immediately" and "decidedly." Perception was usually experienced with a feeling of "continuity," "confirmation," or "satisfaction." These trials were grouped into a cluster SR, characterized by the subjects being in a state of 'steady readiness'.

- Fragmented Readiness. In other trials, subjects reported that they had made a voluntary effort to be ready, but were prepared either less "sharply" (due to a momentary "tiredness") or less "focally" (due to small "distractions," "inner speech," or "discursive thoughts"). The emergence of the 3D image was experienced with a small feeling of surprise or "discontinuity." These trials formed a second cluster corresponding to a state of 'fragmented readiness'.

- Unreadiness (Spontaneous Unreadiness, Self-Induced Unreadiness). In the remaining trials, subjects reported that they were unprepared and saw the 3D image only 
because their eyes were correctly positioned. They were surprised by it and reported that they were "interrupted" by the image in the middle of a thought (memories, projects, fantasies, etc.). This state of distraction occurred spontaneously for subjects $\mathrm{S} 1$ and S4, whereas S2 and S3 triggered it either by fantasizing or by thinking about plans (S3), or by visualizing a mental image (S2). To separate passive and active distraction, these trials were divided into two different clusters, 'spontaneous unreadiness' for S1 and S4, and 'self-induced unreadiness' for S2 and S3. ${ }^{23}$

These phenomenal invariants found in the training session were used to divide the individual trials of the recording session into corresponding phenomenological clusters. The EEG signals were analyzed to determine the transient patterns of local and longdistance phase-synchronies between electrodes, and separate dynamical analyses of the signals were conducted for each cluster. The phenomenological clusters were thus used as a heuristic to detect and interpret neural activity. The hypothesis was that distinct phenomenological clusters would be characterized by distinct dynamical neural signatures before stimulation (reflecting state of preparation), and that these signatures would then differentially condition the neural and behavioural responses to the stimulus. To test this hypothesis, the behavioural data and the EEG data were analyzed separately for each cluster.

The overall result was that original dynamical categories of neural activity were detected, and hence the opacity in brain responses (due to their intrinsic variability) was reduced. For an example, we can consider the contrast between the two clusters of Steady Readiness and Spontaneous Unreadiness for one of the subjects. In the first cluster, the subject reported being prepared for the presentation of the stimulus, with a feeling of continuity when the stimulation occurred and an impression of fusion between himself and the percept. In the second cluster, the subject reported being unprepared, distracted, and having a strong feeling of discontinuity in the flux of his mental states when the stimulus was presented. He described a clear impression of differentiation between

\footnotetext{
${ }^{23} \mathrm{An}$ intermediate cluster between the first and second clusters was defined for subject $\mathrm{S} 3$. This state was described as one of open attention without active preparation. It was unique to this subject who found that this state contrasted sharply with that of prepared steady readiness.
} 
himself and the percept. These distinct features of subjective experience were correlated with distinct dynamical neural signatures (in which phase-synchrony and amplitude were rigorously separated in the dynamical analysis). During steady preparation, a frontal phase-synchronous ensemble emerged early between frontal electrodes and was maintained on average throughout the trial, correlating with the subject's impression of continuity. The average reaction time for this group of trials was short (300 milliseconds on average). The energy in the gamma band $(30-70 \mathrm{~Hz})$ increased during the preparation period leading up to the time of stimulus presentation. This energy shift toward the gamma band occurred in all subjects and was specific to the 'prepared' clusters. The energy in the gamma band was always higher in anterior regions during the pre-stimulus period for subjects in the 'prepared' clusters than for subjects in the 'unprepared' clusters, whereas the energy in the slower bands was lower. These results suggest that the deployment of attention during the preparation strategy was characterized by an enhancement of the fast rhythms in combination with an attenuation of the slow rhythms. On the other hand, in the unprepared cluster, no stable phase-synchronous ensemble can be distinguished on average during the pre-stimulus period. When stimulation occurred, a complex pattern of weak synchronization and massive desynchronization or phasescattering between frontal and posterior electrodes was revealed. A subsequent frontal synchronous ensemble slowly appeared while the phase-scattering remained present for some time. In this cluster the reaction time was longer (600 milliseconds on average). The complex pattern of synchronization and phase-scattering could correspond to a strong reorganization of the brain dynamics in an unprepared situation, delaying the constitution of a unified cognitive moment and an adapted response. This discontinuity in the brain dynamics was strongly correlated with a subjective impression of discontinuity.

Apart from these patterns common to all subjects, it was also found that the precise topography, frequency, and time course of the synchrony patterns during the preparation period varied widely across subjects. These variations should not be treated as 'noise', however, because they reflect distinct dynamical neural signatures that remained stable in individual subjects throughout several recording sessions over a number of days. 
In summary, this study demonstrated (i) that first-person data about the subjective context of perception can be related to stable phase-synchrony patterns measured in EEG recordings before the stimulus; (ii) the states of preparation and perception, as reported by the subjects, modulated both the behavioural responses and the dynamic neural responses after the stimulation; and (iii) although the precise shape of these synchrony patterns varied among subjects, they were stable in individual subjects throughout several recording sessions, and therefore seem to constitute a consistent signature of a subject's cognitive strategy or aptitude to perform the perceptual task. More generally, by using first-person methods to generate new first-person data about the structure of subjective experience, and using these data to render intelligible some of the opacity of the brain response, this pilot study illustrates the validity and fruitfulness of the neurophenomenological approach.

\section{Waves of Consciousness}

As James and Husserl discussed at great length, conscious experience appears from the first-person perspective as an unceasing yet continually changing flow of moments of awareness. Is it possible to take account of this phenomenal temporality while studying the brain mechanisms underlying consciousness? This question motivated the second study, in which binocular rivalry and magnetoencephalography (MEG) were used to investigate the temporal dynamics of brain activity during conscious perception.

When two different visual patterns are presented simultaneously, one to each eye, the patterns are seen as alternating back and forth at irregular intervals, a phenomenon known as binocular rivalry. In binocular rivalry, as in other forms of multistable perception, the perception changes while the visual stimulation remains the same. Binocular rivalry has thus been used as a probe for finding the neural processes associated specifically with the content of a moment of conscious perception. ${ }^{24}$ Yet binocular rivalry also offers an ideal experimental condition to assess the dynamics of cortical activity during ongoing conscious perception, because the perception of a given stimulus fluctuates spontaneously and unpredictably in time.

\footnotetext{
${ }^{24}$ See Blake (2001) and Blake and Logothetis (2002) for reviews.
} 
The rivalrous stimuli used in this experiment were an image of a face and an image of a series of expanding checkerboard rings. The subject was instructed to indicate when one or the other image became dominant by pressing one or the other of two buttons. The expanding rings spanned from 0 to 4 degrees of visual eccentricity five times per second, producing a concomitant evoked cortical response at 5 hertz. This spanning velocity was thus used as a 'frequency tag' to mark neural activity and thereby guide the localization of the cortical network specifically evoked by this pattern and the modulation of this network throughout successive dominance and suppression periods.

Prior to the recording session, subjects familiarized themselves extensively with the rivalry experience for these stimuli. They gave detailed phenomenological accounts, guided by the second-person method of open questions asked by the experimenter (Petitmengin-Peugeot 1999). From these descriptions, the following structural invariant of experience was found to be strictly valid for all subjects: during binocular rivalry, periods of dominance are recurrent through time, while the transitions between periods of dominance are highly variable in the way they arise. Although highly general, this invariant is nonetheless a significant constraint on the detection and interpretation of the underlying neural activity. In particular, one can hypothesize that in binocular rivalry, cortical activity during conscious perception may exhibit a corresponding structure of recurrent dynamic patterns with highly variable transitions. ${ }^{25}$

Testing this hypothesis requires an approach that can map recurrent brain sources with no restrictions on the temporal sequence of their activation, and that can explicitly

\footnotetext{
${ }^{25}$ This hypothesis is reminiscent of Köhler's principle of isomorphism. In Gestalt Psychology, Köhler states: "The principle of isomorphism demands that in a given case the organization of experience and the underlying physiological facts have the same structure" (1947, p. 301). But there is an important difference. Kohler presents isomorphism as a principle that demands a structural correspondence between experience and physiology; hence his view seems to require isomorphism as an a priori condition of any successful explanation. Pessoa, Thompson, and Noë (1998) call this view analytic isomorphism. The above conjecture, on the other hand, is stated as a working hypothesis, rather than a principle. The conjecture serves as a heuristic constraint that guides the search for dynamic patterns of neural activity pertinent to consciousness. Isomorphism serves as a working a tool for tracking brain dynamics at the level of largescale integration, not as an explanatory principle. For further discussion of issues about isomorphism see Pessoa, Thompson, and Noë (1998) and Noë and Thompson (2004a).
} 
take into account the variable dynamics of the perceptual transitions without averaging, which could destroy potentially relevant information. Hence novel source localization techniques (for inferring underlying cortical activity from MEG data) and statistical analyses (for studying recurrence and variability without averaging) were developed and tested (David, Garnero, Cosmelli, and Varela 2002; David, Cosmelli, Hasboun, and Garnero 2003).

Phase synchrony analysis was performed on the brain signals reconstructed from the MEG data using these source localization and statistical techniques. The hypothesis was that during conscious perception of the 5 hertz rings, phase synchrony in this frequency band would rise and fall in concert with perceptual dominance. A consistent correlation between the time course of the synchronization of the cortical network and alternations in conscious perception was found. Thus overall evoked cortical synchrony correlated with conscious perception. To analyze the spatiotemporal dynamics of the specific cortical networks engaged during conscious perception, the ongoing pattern of synchronous brain activity throughout a series of perceptual transitions was followed. A dynamic buildup of the synchronous network was apparent throughout the perceptual alternations. At the beginning of each transition, very few synchronous pairs were evident. As perceptual dominance developed, the occipital pole showed an increase in local synchrony involving primary visual cortex and more dorsal occipital areas. Longrange co-activation was then established between occipital regions and more frontal areas, including mainly medial frontal regions. This pattern of occipito-frontal distributed network was maintained for several seconds, and coincided with full perceptual dominance of the tagged expanding checkerboard rings. Then, as suppression began, long-range synchronous activity fell apart, leaving coactive areas in the occipital pole, and in some cases, inferotemporal regions up to the temporal pole. During full suppression very few co-active regions were left and brain patterns returned to the pretransition situation. This study thus presented for the first time ongoing patterns of cortical synchronous activation that correlate with the spontaneous stream of conscious perception. 
8. Neurophenomenology and the Neural Correlates of Consciousness A currently popular style of investigation is to search for the neural correlates of consciousness (or NCCs) (Metzinger 2000; Rees, Kreiman, and Koch 2002). The term 'correlate' is potentially misleading, however, for the goal is to discover not mere correlates, but neural events that are sufficient for the contents of consciousness (Kanwisher 2001), as can be seen from this definition of an NCC:

An NCC (for content) is a minimal neural representational system $\mathrm{N}$ such that representation of a content in $\mathrm{N}$ is sufficient, under conditions $\mathrm{C}$, for representation of that content in consciousness (Chalmers 2000, p. 31).

As this definition makes plain, the content-NCC approach is based on the assumption that the contents of consciousness match the contents of neural representational systems. Noë and Thompson (2004a) call this assumption the matching content doctrine. According to the matching content doctrine, for every conscious experience $E$, there is a neural representational system $N$, such that (i) $N$ is the minimal neural representational system whose activation is sufficient for $E$, and (ii) there is a match between the content of $E$ and the content of $N$.

The matching content doctrine goes hand-in-hand with a particular research strategy, which Searle (2000) has called the building block model of consciousness. The building block approach proceeds by trying to isolate neural correlates of the contents of consciousness for specific types of individual sensory experiences, such as the visual experience of a perceptually dominant stimulus in binocular rivalry. Although this NCC approach is "initially neutral on issues of causality" (Rees, Kreiman, and Koch 2002, p. 261), the ultimate aim is to determine not mere correlates of individual (types of) conscious states, but the causally necessary and sufficient conditions of these states, including a theory or model of the neurophysiological mechanisms involved. The conjecture is that if we could determine the content NCCs for a particular sort of conscious experience, such as the visual experience of colour or faces, or perhaps visual experience in general, this finding might generalize to other sorts of conscious experiences (Crick and Koch 1998). To put it another way, if we could determine for 
colour vision, or vision in general, what makes a given content a phenomenally conscious content, then we might be able to determine what makes a content conscious for any modality.

There are a number of problems with both the matching content doctrine and the building block model, and hence with this NCC approach overall (Noë and Thompson 2004a, 2004b). First, although neural correlates of various types of conscious states have been found experimentally, these correlates do not provide any case of a match between the content of a neural system and the content of a conscious state. For example, there is no content match between a population of cells whose content is specified in terms of the receptive field properties of single neurons and the perceptual content of seeing the image of a face in binocular rivalry. Second, it is doubtful that neural systems, at least as standardly conceived in much of the NCC literature, could match conscious states in content, as a result of the logical and conceptual differences between these two sorts of content (Noë and Thompson 2004a). Indeed, it is not unreasonable to think that the very notion of a content match between the level of neurons and the level of consciousness is a category mistake (Tononi and Edelman 1998; Searle 2004). Third, it is problematic to assume that consciousness is made up of various building blocks corresponding to constituent individual experiences, which are then somehow bound together to constitute the unity (or apparent unity) of consciousness. As Searle points out: "Given that a subject is conscious, his consciousness will be modified by having a visual experience, but it does not follow that the consciousness is made up of various building blocks of which the visual experience is just one" (Searle 2000, p. 572). Finally, to remain "initially neutral on issues of causality" is a significant limitation, given the need to investigate the hypotheses that (i) each conscious state (on a fraction-of-a-second time scale) involves the transient selection of a large-scale dynamic neural assembly, and (ii) that the global behaviour of such an assembly modulates and constrains local neural activity, and thereby causally influences mental processes and intentional action (Freeman 1999b; Thompson and Varela 2001; Le Van Quyen and Petitmengin 2002). More generally, in postponing issues of causality, the NCC approach avoids what Dennett calls "the Hard Question-And Then What Happens?" (Dennett 1991, p. 255; 2001, p. 225). In other words, the NCC approach runs the risk of treating consciousness as simply the end of the 
line, instead of asking not only what activity is causally necessary and sufficient for consciousness, but also what causal difference that activity makes for other brain processes and the organism overall.

In presenting and criticizing the building block model, Searle (2000) also singles out a different approach to the brain basis of consciousness, which he calls the unified field model. Searle argues that the neural substrates of individual conscious states should not be thought of as sufficient for the occurrence of those states, for those states themselves presuppose the background consciousness of the subject. Any given conscious state is a modulation of a pre-existing conscious field. According to this unified field approach, an individual experience or conscious state (such as visual recognition of a face) is not a constituent (in the building block sense) of some aggregate conscious state, but is rather a modification within the field of a basal or background consciousness: "Conscious experiences come in unified fields. In order to have a visual experience, a subject has to be conscious already, and the experience is a modification of the field" (Searle 2000, p. 572) ${ }^{26}$ The unified field approach accordingly focuses on (i) the neural basis of the whole unified field at the level of large-scale activity, rather than neural correlates for the contents of particular conscious states; (ii) the neurophysiological processes that characterize the dynamic modulation of the conscious field in time; and (iii) the differences in brain activity across basal or background states, such as dreamless sleep, dreaming, wakefulness, and so on.

Neurophenomenology is consistent with the unified field model. As Searle notes, according to the unified field approach, "what we have to look for is some massive activity of the brain capable of producing a unified holistic conscious experience" ( $p$ 574). One of the working hypotheses of neurophenomenology is that this massive activity is large-scale integration via phase synchrony (or more complex forms of generalized synchrony). This global self-organization is metastable (new patterns constantly arise without the system settling down into any one of them), rapid (occurring on a time scale of 100 to 300 milliseconds), and constitutes a fundamental pole of integration for the selection and modulation of local neuronal activity. It needs to be emphasized that this

\footnotetext{
${ }^{26}$ The idea of consciousness as a unified field of subjective experience has of course long been central to phenomenology (e.g., Gurwitsch 1964).
} 
'core hypothesis' (Varela 1995) is not meant as a hypothesis about what makes a particular brain process a neural correlate of the content of a particular conscious state. Rather, it is meant to be a hypothesis about what differentiates the neural activity that directly contributes to the emergence of a coherent (unified) conscious state from other neural activity going on in the nervous system.

We need to distinguish, however, between a momentary state of unified consciousness and basal consciousness in the sense of being awake and alert. This is the distinction between state consciousness and background consciousness (see Section 4). Searle's proposal is that states of consciousness arise as modifications of the field of basal consciousness, but he does not clearly differentiate between the two notions of state consciousness and background consciousness. The distinction is important, however, not only conceptually and phenomenologically, but also neurophysiologically. On the one hand, there is good reason to believe, as Searle notes following Tononi and Edelman (1998) and Llinas, Ribary, Contreras, and Pedroarena (1998), that the coherent largescale activity that characterizes a transient unified conscious state occurs in thalamocortical networks. Strong cortico-cortical and cortico-thalamic projections are capable of generating a coherent neural process on a fast time-scale (100 to 300 milliseconds) through on-going re-entrant, recursive, and highly parallel interactions among widely distributed brain areas. On the other hand, basal consciousness, in the sense of being awake and alert, depends fundamentally on brainstem structures and processes (Parvizi and Damasio 2001). Furthermore, basal consciousness includes a primary affective awareness or core consciousness of self (Panksepp 1998b; Damasio 1999). Hence it seems unsatisfactory to say that consciousness, in the sense of a single, unified conscious field, "is in large part localized in the thalamocortical system and that various other systems feed information to the thalamocortical system that produces modifications corresponding to the various sensory modalities" (Searle 2000, p. 574). Although the thalamocortical system is clearly crucial for transient conscious states on a millisecond time scale, midbrain and brainstem structures are crucial for affective core consciousness or sentience. Thus virtually the entire neuraxis seems essential for consciousness in the widest sense of the term (Watt 1999). 
The experimental neurophenomenological studies reviewed above are also more consistent with a unified field model than a building block model. Consider first the binocular rivalry study. Binocular rivalry has been one of the main experimental paradigms for the content NCC approach. In the NCC literature, binocular rivalry is usually presented as revealing a competition between two separate and distinct states that alternately become conscious. The research task is to discover the neural activity that represents what the subject sees (the content NCC) for each distinct conscious state (Crick 1996). Each conscious state is treated, in effect, as a building block of a composite rivalry experience. Noë and Thompson (2004a, pp. 24-25) have argued, however, that careful phenomenological examination suggests the experience of rivalry is not composite in the building block sense: it is not a composite experience having the normal (nonrivalrous) experience of one image and the normal (nonrivalrous) experience of the other image as constituent repeating elements. Rather, it seems better described as one bistable experience. In other words, the bistable experience of seeing a face/expanding checkerboard ring (for example) is not equivalent to the normal experience of seeing a face, plus the normal experience of seeing an expanding checkerboard ring, plus the two alternating with the appropriate temporal dynamics. As a bistable perception, it is a unique sort of experience, which accordingly must be assessed on its own terms. Kelso (1995) takes precisely this approach to the perception of multistable figures such as the Necker cube, describing this kind of perception as a metastable state. The neurophenomenological study of binocular rivalry develops this approach further. It takes a dynamic structural approach, rather than a building block or content NCC approach. The temporal dynamics of rivalry is considered to be constitutive of the experience (rather than an added element in building block fashion). By taking into account detailed phenomenological accounts of rivalry, a dynamic pattern of recurrence with highly variable transitions is revealed to be a structural invariant of the rivalry experience, a pattern irreducible to an alternation of two stable and clearly differentiated perceptual experiences (Cosmelli 2004). Using this structural invariant as a guide to detect and interpret neural activity, the neurophenomenological approach is able to show that ongoing patterns of cortical synchronization and desynchronization correlate with fluctuations of conscious perception. 
The neurophenomenological study of depth perception provides a particularly nice case for the unified field model. This study examines "modifications of the already existing field of qualitative subjectivity" (Searle 2000, p. 563), in the form of modifications of perceptual experience that depend on the subjective experience of readiness or unreadiness. To map the neurodynamics of ongoing conscious states, this study makes use of both proximal and distant baselines, corresponding respectively to the one second period immediately before stimulation, and the seven second preparation period leading up to stimulation. Using the proximal baseline enhances the contrast between the synchronous process immediately preceding the arrival of the stimulation and those processes triggered by the stimulation, whereas using the distant baseline reveals a resemblance in synchrony patterns between prestimulus activity and the response induced by the stimulation. From a unified field perspective, these two baselines correspond to different time slices of the conscious field. The distant baseline takes in more, as it were, of the pre-existing field of subjective experience, and thus reveals patterns of dynamic activity that are not seen using the proximal baseline. It also enables one to show that the pre-existing conscious field is not only modified by, but also differentially conditions the emergence of the 3D image. Described phenomenologically, the subjective context of readiness/unreadiness leading up to perception is a noetic factor of the field of experience, which differentially conditions the noematic factor of the quality of the depth percept. This neurophenomenological study thus focuses on the dynamic noetic/noematic structure of the 'field of consciousness' (Gurwitsch 1964).

Given the results of this study, it seems appropriate to redefine the temporal interval of interest for the neural correlate of a conscious act. The correlate of depth perception obviously occurs between the appearance of the stimulus and the motor response. Yet this moment of consciousness extends from a previous one, and finds its place within a temporal horizon of retention and anticipation that cannot be seen as neutral (Varela 1999). Hence the characterization of both the ongoing activity preceding the stimulation and the activity following it is necessary for a complete description of the dynamics of a moment of consciousness. This point is also borne out by the binocular rivalry study, in which the temporal dynamics of fluctuations in perception is constitutive of the experience. 
The last point we wish to make in this section concerns the issue of causality. We believe that neurophenomenology can not only produce original dynamic NCC data (in contrast to building block/content NCC data), but can also help illuminate the causal principles involved in conscious activity. For instance, it seems natural to interpret the depth perception study in terms of the dynamic systems principle of circular causality, in which local events self-organize into global coherent patterns that in turn modulate and constrain local events (see Freeman 1999b; Thompson and Varela 2001). Thus the antecedent and 'rolling' subjective-experiential context modulates the way the perceptual object appears or is experientially lived during the moment of perception, and the content of this momentary conscious state reciprocally affects the flow of experience. At a neurodynamical level, the brain response presumably results from the intertwining of the endogenous brain activity and the peripheral afferent activity evoked by the stimulus. Therefore, the way the stimulus is directly lived by the subject (as indicated by disciplined phenomenological reports using first-person methods) could serve as a heuristic to shed light on the causal principles by which local afferent activity both modulates and is modulated by the contextual influence of the current large-scale neural assembly, such that this local activity either participates in, or is discarded from, the emergence of the following large-scale assembly. According to this perspective, a moment of consciousness is realized in the brain as a dynamic global state variable that constrains local activities (Freeman 1999b; Thompson and Varela 2001). Or as Kelso puts it: "Mind itself is a spatiotemporal pattern that molds the metastable dynamic patterns of the brain" (Kelso 1995, p. 288).

\section{Conclusion}

We began this paper by mentioning a number of issues associated with the explanatory gap. As we have seen, the neurophenomenological strategy for dealing with the epistemological and methodological issues about first-person data is to employ firstperson methods in tandem with third-person methods. But what about the explanatory gap in the distinctly philosophical sense of the conceptual gap between subjective experience and neurobiology? 
We wish to distinguish between the explanatory gap as a scientific problem and the hard problem of consciousness in the philosophy of mind. The explanatory gap as a scientific problem is the problem of presenting a model that can account for both the phenomenology and neurobiology of consciousness in an integrated and coherent way. The hard problem is an abstract metaphysical problem about the place of consciousness in nature (Chalmers 1996). This problem is standardly formulated as the issue of whether it is conceptually possible to derive subjective experience (or phenomenal consciousness) from objective physical nature. If it is possible, then materialism or physicalistic monism is supposed to gain support; if it is not possible, then property dualism (or panpsychism or idealism) is supposed to gain support.

Although Varela (1996) originally proposed neurophenomenology as a 'methodological remedy for the hard problem', a careful reading of this paper indicates that he did not aim to address the metaphysical hard problem of consciousness on its own terms. The main reason, following analyses and arguments from phenomenological philosophers (e.g., Merleau-Ponty 1962), is that these terms - in particular the Cartesian conceptual framework of the 'mental' versus the 'physical' - are considered to be part of the problem, not part of the solution. From a phenomenological perspective, Cartesian concepts of the mental and the physical cannot be allowed to govern the problem of consciousness. Space prevents further discussion of this point here (see Thompson forthcoming).

With regard to the explanatory gap as a scientific problem, our view is that one of the main obstacles to progress has to do with the way the conscious subject is mobilized in the experimental protocols of neuroscientific research on consciousness. Experimental investigations of the neural correlates of consciousness usually focus on one or another particular feature of experience, and accordingly try both to control as much as possible any variability in the content of subjective experience and to minimize reliance on the subject's verbal reports. Yet this approach seems too limited for investigating the labile, spontaneous, and self-affecting character of conscious processes and brain activity. ${ }^{27}$

\footnotetext{
${ }^{27}$ See Varela (1999); Friston (2000a, 2000b); Lutz (2002); Hanna and Thompson (2004); and Cosmelli (2004).
} 
Thus it is hard to see how this approach could ever bridge the gap between subjective experience and neurobiology.

We believe that a more fruitful way for the experimentalist to investigate these sorts of complex subjective and neurodynamical processes, and to define and control the variables of interest, is to make extensive use of the first-person perspective, approached in a phenomenologically disciplined way. Hence neurophenomenology, without denying the validity of trying to control experimentally the subjective context from the outside, favours a complementary 'endogenous' strategy based on using first-person methods. By enriching our understanding of subjective experience through such phenomenological investigations, and using these investigations to cast light on neurodynamics, neurophenomenology aims to narrow the epistemological and methodological distance between subjective experience and brain processes in the concrete context of the working neuroscientist. At a more abstract conceptual level, neurophenomenology aims not to close the explanatory gap (in the sense of conceptual or ontological reduction), but rather to bridge the gap by establishing dynamic reciprocal constraints between subjective experience and neurobiology. At the present time, neurophenomenology does not claim to have constructed such bridges, but only to have proposed a clear scientific research program for making progress on that task.

\section{References}

Austin, J. 1998. Zen and the Brain. Cambridge, MA: The MIT Press.

Baars, B.J. 2002. The conscious access hypothesis: origins and recent evidence. Trends in Cognitive Sciences 6: 47-52.

Bitbol, M. 2002. Science as if situation mattered. Phenomenology and the Cognitive Sciences 1: 181-224.

Blake, R. 2001. A primer on binocular rivalry, including current controversies. Brain and Mind 2: 5-38.

Blake, R. and Logothetis, N. 2002, Visual competition. Nature Reviews Neuroscience 3: $1-11$. 
Block, N. 1997. On a confusion about a function of consciousness. In N. Block, O. Flanagan, and G. Güzeldere (eds.), The Nature of Consciousness: Philosophical Debates, pp. 375-416. Cambridge, MA: The MIT Press/A Bradford Book.

Block, N. 2001. Paradox and cross purposes in recent work on consciousness. Cognition 79: 197-219.

Botero, J.-J. 1999. The immediately given as ground and background. In J. Petitot, F.J. Varela, B. Pachoud, and J.-M. Roy (eds.), Naturalizing Phenomenology: Issues in Contemporary Phenomenology and Cognitive Science, pp. 440-463. Stanford, CA: Stanford University Press.

Burge, T. 1997. Two kinds of consciousness. In N. Block, O. Flanagan, and G. Güzeldere (eds.), The Nature of Consciousness: Philosophical Debates, pp. 427-434. Cambridge, MA: The MIT Press/A Bradford Book.

Chalmers, D. 1996. The Conscious Mind. New York: Oxford University Press.

Chalmers, D.J. 1997. Availability: the cognitive basis of experience? In N. Block, O. Flanagan, and G. Güzeldere (eds.), The Nature of Consciousness: Philosophical Debates, pp. 421-424. Cambridge, MA: The MIT Press/A Bradford Book

Chalmers, D.J. .2000. What is a neural correlate of consciousness? In T. Metzinger (ed.) Neural Correlates of Consciousness, pp. 18-39. Cambridge, MA: The MIT Press.

Church, J. 1997. Fallacies or analyses? In N. Block, O. Flanagan, and G. Güzeldere (eds.), The Nature of Consciousness: Philosophical Debates, pp. 425-426. Cambridge, MA: The MIT Press/A Bradford Book.

Churchland, P.S. 1986. Neurophilosophy: Toward a Unified Science of the Mind-Brain. Cambridge, MA: The MIT Press/A Bradford Book.

Churchland, P.S. 2002. Brainwise. Studies in Neurophilosophy. Cambridge, MA: The MIT Press/A Bradford Book.

Cosmelli, D. 2004. Des montagnes et des vallées: perception consciente et structure dynamique de l'intégration cérebrale chez l'être humain dans l'expérience de rivalité binoculaire. Doctoral Thesis. Ecole Polytechnique.

Cosmelli, D., David, O., Lachaux, J.-P., Martinerie, J., Garnero, L., Renault, B., and Varela, F.J. submitted. Waves of consciousness: ongoing cortical patterns during binocular rivalry. 
Crick, F. and Koch, C. 1998. Consciousness and neuroscience. Cerebral Cortex 8: 97107.

Crick, F. and Koch, C. 2003. A framework for consciousness. Nature Neuroscience 6: 119-126.

Damasio, A.R. 1990. Synchronous activation in multiple cortical regions: a mechanism for recall. Seminars in the Neurosciences 2: 287-297.

Damasio, A.R. 1999. The Feeling of What Happens: Body and Emotion in the Making of Consciousness. New York: Harcourt Brace.

David, O., Garnero, L., Cosmelli, D., and Varela, F.J. 2002. Estimation of neural dynamics from MEG/EEG cortical current density maps: application to the reconstruction of large-scale cortical synchrony. IEEE Transactions on Biomedical Engineering 49: 975-987.

David, O., Cosmelli, D., Hasboun, D. and Garnero, L. 2003. A multitrial analysis for revealing significant corticocortical networks in magentoencaphalography and electroencephalography. Neuroimage 20: 186-201.

David, O., Cosmelli, D., Lachaux, J.-P., Baillet, S., Garnero, L., and Martinerie, J. 2003. A theoretical and experimental introduction to the non-invasive study of largescale neural phase-synchronization in human beings (invited paper). International Journal of Computational Cognition (http://www.YangSky.com/yangijcc.htm ) 1: 53-77.

David, O., Cosmelli, D., and Friston, K.J. 2004. Evaluation of a different measures of functional connectivity using a neural mass model. Neuroimage 21: 659-673.

Davidson, R.J., Kabat-Zinn, J., Schumacher, J., Rosenkranz, M., Muller, D., Santorelli, S.F., Urbanowski, F., Harrington, A., Bonus, K., and Sheridan, J.F. 2003.

Alterations in brain and immune function produced by mindfulness meditation. Psychosomatic Medicine 65:564-570.

Dehaene, S. and Naccache, L. 2001. Towards a cognitive neuroscience of consciousness: basic evidence and a workspace framework. Cognition 79: 1-37.

Dennett, D.C. 1991. Consciousness Explained. Boston: Little Brown. 
Dennett, D.C. 1997. The path not taken. In N. Block, O. Flanagan, and G. Güzeldere (eds.), The Nature of Consciousness: Philosophical Debates, pp. 417-420. Cambridge, MA: The MIT Press/A Bradford Book.

Dennett, D.C. 2001. Are we explaining consciousness yet? Cognition 79, 221-237.

Dennett, D.C. and Kinsbourne, D.C. 1992. Time and the observer: there where and when of consciousness in the brain. Behavioral and Brain Sciences 15: 183-247.

Depraz, N. 1999. The phenomenological reduction as praxis. In F.J. Varela and J. Shear (eds.), The View from Within: First-Person Approaches to the Study of Consciousness, pp. 95-110, Thorverton, UK: Imprint Academic.

Depraz, N. and Cosmelli, D. 2004. Empathy and openness: practices of intersubjectivity at the core of the science of consciousness. In E. Thompson (ed.), The Problem of Consciousness: New Essays in Phenomenological Philosophy of Mind. Canadian Journal of Philosophy. Supplementary Volume. Calgary, AL: University of Alberta Press.

Depraz, N., Varela, F.J., and Vermersch, P. 2000. The gesture of awareness: an account of its structural dynamics. In M. Velmans (ed.), Investigating Phenomenal Consciousness, pp. 121-136. Amsterdam and Philadelphia: John Benjamins Press.

Depraz, N., Varela, F.J., and Vermersch, P. 2003. On Becoming Aware. Amsterdam and Philadelphia: John Benjamins Press.

Derryberry, D. and Tucker, D.M. 1994. Motivating the focus of attention. In P.M. Niedenthal and S. Kitayama (eds.), The Heart's Eye: Emotional Influences in Perception and Attention, pp. 167-196. New York: Academic Press.

Dreyfus, H. 1991. Being-In-The-World: A Commentary on Heidegger's Being and Time, Division I. Cambridge, MA: The MIT Press.

Dreyfus, H. 2002. Intelligence without representation-Merleau-Ponty's critique of mental representation. Phenomenology and the Cognitive Sciences 1: 367-383.

Dreyfus, H. and Dreyfus, S. 1982. Mind over Machine. New York: Free Press.

Ellis, R. 2001. Implications of inattentional blindness for 'enactive' theories of consciousness. Brain and Mind 2: 297-322.

Engel, A. and Singer, W. 2001. Temporal binding and the neural correlates of sensory awareness. Trends in Cognitive Sciences 5: 16-25. 
Engel, A.K., Fries, P., and Singer, W. 2001. Dynamic predictions: oscillations and synchrony in top-down processing. Nature Reviews Neuroscience 2: 704-716.

Epstein, M. 1996. Thoughts without a Thinker. New York: Basic Books.

Foreman, R.K.C. (ed.) 1990. The Problem of Pure Consciousness. New York: Oxford University Press.

Freeman, W.J. 1999a. How Brains Make up their Minds. London: Weidenfeld and Nicolson.

Freeman, W. 1999b. Consciousness, intentionality, and causality. Journal of Consciousness Studies 6: 143-172.

Freeman, W.J. 2000. Emotion is essential to all intentional behaviors. In M. Lewis and I. Granic (eds.), Emotion, Development, and Self-Organization, pp. 209-235. Cambridge: Cambridge University Press.

Fries, P., Reynolds, J.H., Rorie, A.E., and Desimone, R. 2001. Modulation of oscillatory neuronal synchronization by selective visual attention. Science 291: 1560-1563.

Friston, K.J. 2000a. The labile brain. I. Neuronal transients and nonlinear coupling. Philosophical Transactions of the Royal Society of London B 355: 215-236.

Friston, K.J. 2000b. The labile brain. II. Transients, complexity, and selection. Philosophical Transactions of the Royal Society of London B 355: 237-252.

Frith, C. 2002. How can we share experiences? Trends in Cognitive Sciences 6, 374.

Gallagher, S. 1986. Lived body and environment. Research in Phenomenology 16: 139170.

Gendlin, E.T. 1981. Focusing. New York: Bantam.

Gupta, B. 1998. The Disinterested Witness. Evanston, IL: Northwestern University Press. Gurwitsch, A. 1964. The Field of Consciousness. Pittsburgh, PA: Dusquesne University Press.

Hanna, R. and Thompson, E. 2004. Neurophenomenology and the spontaneity of consciousness. In E. Thompson (ed.), The Problem of Consciousness: New Essays in Phenomenological Philosophy of Mind. Canadian Journal of Philosophy Supplementary Volume. Calgary, AL: University of Alberta Press.

Heidegger, M. 1996. Being and Time. Trans. J. Stambaugh. Albany, NY: State University of New York Press. 
Hobson, J.A. 1999. Consciousness. New York: W.H. Freeman.

Hurlbert, R.T. and Heavey, C.L. 2001. Telling what we know: describing inner experience. Trends in Cognitive Sciences 5, 400-403.

Hurley, S.L. and Noë, A. 2003. Neural plasticity and consciousness. Biology and Philosophy 18: 131-168.

Husserl, E. 2001. Analyses Concerning Passive and Active Synthesis. Lectures on Transcendental Logic. (Steinbock, A.J. trans.). Dordrecht: Kluwer Academic Publishers.

Jack, A.I. and Roepstorff, A. 2002. Introspection and cognitive brain mapping: from stimulus-response to script-report. Trends in Cognitive Sciences 6, 333-339.

Jack, A.I. and Roepstorff, A. (eds.) 2003. Trusting the Subject? The Use of Introspective Evidence in Cognitive Science. Volume 1. Thorverton, UK: Imprint Academic.

Jack, AI. and Shallice, T. 2001. Introspective physicalism as an approach to the science of consciousness. Cognition 79, 161-196.

Jonas, H. 1966. The Phenomenon of Life. Chicago: University of Chicago Press.

Kabat-Zinn J. 1990. Full Catastrophe Living. Using the Wisdom of Your Body and Mind to Face Stress, Pain, and Illness. New York: Dell.

Kahana, M.J., Seelig, D., and Madsen, J.R. 2001. Theta returns. Current Opinion in Neurobiology 11: 739-744.

Kanwisher, N. 2001. Neural events and perceptual awareness. Cognition 79: 89-113.

Kelso, J.A.S. 1995. Dynamic Patterns: The Self-Organization of Brain and Behavior. Cambridge, MA: The MIT Press.

Köhler, W. 1947. Gestalt Psychology. New York: Liveright.

Kriegel, U. 2003. Consciousness as intransitive self-consciousness: two views and an argument. Canadian Journal of Philosophy 33: 103-132.

Kuhn, T. 1970. The Stucture of Scientific Revolutions. Chicago: University of Chicago Press.

Lachaux, J.-P., Rodriguez, E., Martinerie, J., and Varela, F.J. 1999. Measuring phase synchrony in brain signals. Human Brain Mapping 8: 194-208. 
Lachaux, J.-P., Chavez, M., and Lutz, A. 2003. A simple measure of correlation across time, frequency and space between continuous brain signals. Journal of Neuroscience Methods 123: 175-188.

Lambie, J.A. and Marcel, A.J. 2002. Consciousness and the varieties of emotion experience: a theoretical framework. Psychological Review 109: 219-259.

Le Van Quyen, M. and Petitmengin, C. 2002. Neuronal dynamics and conscious experience: an example of reciprocal causation before epileptic seizures. Phenomenology and the Cognitive Sciences 1, 169-180.

Le Van Quyen, M. 2003. Disentangling the dynamic core: a research program for neurodynamics at the large scale. Biological Research 36: 67-88.

Lewis, M.D. 2000. Emotional self-organization at three time scales. In M.D. Lewis and I. Granic (eds.). Emotion, Development, and Self-Organization. Dynamic Systems Approaches to Emotional Development, pp. 37-69. Cambridge and New York: Cambridge University Press.

Lewis, M.D. in press. Bridging emotion theory and neurobiology through dynamic systems modeling. Behavioral and Brain Sciences.

Llinas, R., Ribary, U., Contreras, D., and Pedroarena, C. 1998. The neuronal basis for consciousness. Philosophical Transactions of the Royal Society of London Series B 353: 1801-1818.

Lutz, A. 2002. Toward a neurophenomenology as an account of generative passages: a first empirical case study. Phenomenology and the Cognitive Sciences 1: 133-167.

Lutz, A. and Thompson, E. 2003. Neurophenomenology: integrating subjective experience and brain dynamics in the neuroscience of consciousness. Journal of Consciousness Studies 10: 31-52.

Lutz, A., Lachaux, J.-P., Martinerie, J., and Varela, F.J. 2002. Guiding the study of brain dynamics by using first-person data: synchrony patterns correlate with ongoing conscious states during a simple visual task. Proceedings of the National Academy of Sciences USA. 99, 1586-1591.

Maturana, H.R. 1969. The neurophysiology of cognition. In P. Garvin (ed.), Cognition: A Multiple View. New York: Spartan Books. 
Maturana, H.R. 1970. Biology of cognition. In H.R. Maturana and F.J. Varela, Autopoiesis and Cognition: The Realization of the Living, pp. 2-58. Boston Studies in the Philosophy of Science. Volume 43. Dordrecht: D. Reidel.

Maturana, H. R. and Varela, F J. 1980. Autopoiesis and Cognition: The Realization of the Living. Boston Studies in the Philosophy of Science, vol. 42. Dordrecht: D. Reidel.

Maturana, H.R. and Varela, F.J. 1987. The Tree of Knowledge. The Biological Roots of Human Understanding. Boston: Shambala Press/New Science Library.

Merleau-Ponty, M. 1962. Phenomenology of Perception (trans. C. Smith). London: Routledge Press.

Metzinger, T. (ed.) 2000. Neural Correlates of Consciousness. Cambridge, MA The MIT Press.

Moran, D. 2000. Introduction to Phenomenology. London: Routledge Press.

Moustakas, C. 1994. Phenomenological Research Methods. Thousand Oaks, London, New Delhi: Sage Publications.

Nagel, T. 1979. What is it like to be a bat?” In T. Nagel, Mortal Questions, pp. 165-180. New York: Cambridge University Press.

Nisbett, R.E. and Wilson, T.D. 1977. Telling more than we can know: verbal reports on mental processes. Psychological Review 84, 231-259.

Noë, A. and Thompson, E. 2004a. Are there neural correlates of consciousness? Journal of Consciousness Studies 11: 3-28.

Noë, A. and Thompson, E. 2004b. Sorting out the neural basis of consciousness. Authors' reply to commentators. Journal of Consciousness Studies 11: 87-98.

Ohl, F.W., Scheich, H., and Freeman, W.J. 2001. Change in pattern of ongoing cortical activity with auditory category learning. Nature 412, 733-736.

O'Keefe, J. and Burgess, N. 1999. Theta activity, virtual navigation and the human hippocampus. Trends in Cognitive Sciences 11, 403-406.

O’Regan, J.K. and Noë, A. 2001. A sensorimotor account of vision and visual consciousness. Behavioral and Brain Sciences 24: 939-1031.

Parvizi, J. and Damasio, A. 2001. Consciousness and the brainstem. Cognition 79, 135159. 
Panskepp, J. 1998a. Affective Neuroscience: The Foundations of Human and Animal Emotions. New York: Oxford University Press.

Panskepp, J. 1998b. The periconscious substrates of consciousness: affective states and the evolutionary origins of self. Journal of Consciousness Studies 5: 566-582.

Pessoa, L., Thompson, E. and Noë, A. 1998. Finding out about filling-in: a guide to perceptual completion for visual science and the philosophy of perception. Behavioral and Brain Sciences 21: 723-802.

Petitot, J., Varela, F.J., Pachoud, B., and Roy, J.-M. (eds.) 1999. Naturalizing Phenomenology. Stanford, CA: Stanford University Press.

Petitmengin, C. 2001. L'expérience intuitive. Paris: L'Harmattan.

Petitmengin-Peugeot, C. 1999. The intuitive experience. In The View from Within (Varela, F.J. and Shear, J. eds.), pp. 43-78. Thorveton, UK: Imprint Academic.

Price, D. and Barrell, J. 1980. An experiential approach with quantitative methods: a research paradigm. Journal of Humanistic Psychology 20: 75-95.

Price, D., Barrell, J., and Rainville, P. 2002. Integrating experiential-phenomenological methods and neuroscience to study neural mechanisms of pain and consciousness. Consciousness and Cognition 11: 593-608.

Rees, G., Krieman, G., and Koch, C. 2002. Neural correlates of consciousness in humans. Nature Reviews Neuroscience 3: 261-270.

Rodriguez, E., George, N., Lachaux, J.P., Martinerie, J., Renault, B., and Varela, F.J. 1999. Perception's shadow: long-distance synchronization of human brain activity. Nature 397: 430-433.

Rosenthal, D.M. 1997. A theory of consciousness. In The Nature of Consciousness (Block, N. et al, eds.), pp. 729-753. Cambridge, MA: The MIT Press.

Roy, J.-M. 2004. Phenomenological claims and the myth of the given. In E. Thompson (ed.), The Problem of Consciousness: New Essays in Phenomenological Philosophy of Mind. Canadian Journal of Philosophy, Supplementary Volume.

Roy, J.-M., Petitot, J., Pachoud, B., and Varela, F.J. 1999. Beyond the gap: an introduction to naturalizing phenomenology. In Naturalizing Phenomenology (Petitot, J., Varela, F.J., Pachoud, B., and Roy, J.-M., eds.), pp. 1-80. Stanford, CA: Stanford University Press. 
Rudrauf, D., Lutz, A., Cosmelli, D., Lachaux, J.-P., and Le Van Quyen, M. 2002. From autopoiesis to neurophenomenology. Biological Research 36: 27-66.

Sarntheim, J., Petsche, H., Rappelsberger, P., Shaw, G.L., and von Stein, A. 1998. Synchronization between prefrontal and posterior association cortex during human working memory. Proceedings of the National Academy of Sciences USA 95: 7092-7096.

Sartre, J.-P. 1956. Being and Nothingness. Trans. Hazel Barnes. New York: Philosophical Library.

Schiff, S.J., So, P., Chang, T., Burke, R.E., and Sauer, T. 1996. Detecting dynamical interdependence and generalized synchrony through mutual prediction in a neural ensemble. Physical Review E 54: 6706-6724.

Schooler, J.W. 2002. Re-representing consciousness: dissociations between experience and meta-consciousness. Trends in Cognitive Sciences 6, 339-344.

Searle, J.S. 1983. Intentionality: An Essay in the Philosophy of Mind. Cambridge and New York: Cambridge University Press.

Searle, J. 2000. Consciousness. Annual Review of Neuroscience 23: 557-578.

Searle, J. 2004. Comments on Noë \& Thompson 'Are there NCCs?' Journal of Consciousness Studies 11: 79-82.

Sellars, W. 1956. Empiricism and the philosophy of mind. In H. Feigl and M. Scriven (eds.), Minnesota Studies in the Philosophy of Science. Volume 1. The Foundations of Science and the Concepts of Psychology and Psychoanalysis, pp. 253-329. Minneapolis, MN: University of Minnesota Press.

Singer, W. 1999. Neuronal synchrony: a versatile code for the definition of relations? Neuron 24, 49-65.

Steinbock, A.J. 1999. Saturated intentionality. In Donn Welton (ed.) The Body, pp. 178199. Oxford: Basil Blackwell.

Thompson, E. 2001. Empathy and consciousness. Journal of Consciousness Studies 8: 132.

Thompson, E. (ed.) 2004. The Problem of Consciousness. New Essays in Phenomenological Philosophy of Mind. Canadian Journal of Philosophy Supplementary Volume. Calgary, AL: University of Alberta Press. 
Thompson, E. forthcoming. Radical Embodiment: The Lived Body in Biology, Human Experience, and the Sciences of Mind. Cambridge, MA: Harvard University Press.

Thompson, E. and Varela, F.J. 2001. Radical embodiment: neural dynamics and consciousness. Trends in Cognitive Sciences 5: 418-425.

Thompson, E. and Zahavi, D. in press. Contemporary Continental perspectives: phenomenology. In P.D. Zelazo and M. Moscovitsch (eds.) The Cambridge Companion to Consciousness. New York and Cambridge: Cambridge University Press.

Thompson, E., Palacios, A., and Varela, F.J. 1992. Ways of coloring: comparative color vision as a case study for cognitive science. Behavioral and Brain Sciences 15: 174. Reprinted in Alva Noë and Evan Thompson (eds.), Vision and Mind: Readings in the Philosophy of Perception. Cambridge, MA: The MIT Press, 2002.

Thompson, E., Noë, A., and Pessoa, L. 1999. Perceptual completion: a case study in phenomenology and cognitive science. In J. Petitot, F.J. Varela, B. Pachoud, and J.-M. Roy (eds.), Naturalizing Phenomenology: Issues in Contemporary Phenomenology and Cognitive Science, pp. 161-195. Stanford, CA: Stanford University Press.

Tononi, G. and Edelman, G.M. 1998. Consciousness and complexity. Science 282, 18461851.

VanRullen, R. and Koch, C. 2003. Is perception discrete or continuous? Trends in Cognitive Sciences 7: 207-213.

Varela, F.J. 1979. Principles of Biological Autonomy. New York: Elsevier North Holland.

Varela, F.J. 1991. Organism: a meshwork of selfless selves. In A. Tauber (ed.), Organism and the Origin of Self, pp. 79-107. Dordrecht: Kluwer Academic Publishers.

Varela, F.J. 1995. Resonant cell assemblies: a new approach to cognitive functions and neuronal synchrony. Biological Research 28, 81-95.

Varela, F.J. 1996. Neurophenomenology: a methodological remedy to the hard problem. Journal of Consciousness Studies 3, 330-350.

Varela, F.J. 1997a. Patterns of life: intertwining identity and cognition. Brain and Cognition 34: 72-87. 
Varela, F.J. 1997b. The naturalization of phenomenology as the transcendence of nature. Alter 5: 355-381.

Varela, F.J. 1999. The specious present: a neurophenomenology of time consciousness. In Naturalizing Phenomenology (Petitot, J. et. al., eds.) pp. 266-314. Stanford, CA: Stanford University Press.

Varela, F.J. and Bourgine, P. (eds.) 1991. Toward a Practice of Autonomous Systems. Proceedings of the First European Conference on Artificial Life (Cambridge, MA: The M IT Press.

Varela, F.J. and Shear, J. (eds.) 1999a. The View from Within: First-Person Approaches to the Study of Consciousness. Thorverton, UK: Imprint Academic.

Varela, F.J. and Shear, J. 1999b. First-person accounts: why, what, and how. In F.J. Varela and J. Shear (eds.), The View from Within: First-Person Approaches to the Study of Consciousness, pp. 1-14. Thorveton, UK: Imprint Academic.

Varela, F.J. and Thompson, E. 2003. Neural synchrony and the unity of mind: a neurophenomenological perspective. In A. Cleeremans (ed.), The Unity of Consciousness: Binding, Integration and Dissociation, pp. 266-287. New York: Oxford University Press.

Varela, F.J., Thompson, E., and Rosch, E. 1991. The Embodied Mind: Cognitive Science and Human Experience. Cambridge, MA: The MIT Press.

Varela, F.J., Lachaux, J.-P., Rodriguez, E., and Martinerie, J. 2001. The brainweb: phase synchronization and large-scale integration. Nature Reviews Neuroscience 2, 229239.

Vermersch, P. 1999. Introspection as practice. In F.J. Varela and J. Shear (eds.), The View from Within: First-Person Approaches to the Study of Consciousness, pp. 17-42. Thorverton, UK: Imprint Academic

von Stein, A. and Sarntheim, J. 2000. Different frequencies for different scales of cortical intergration: from local gamma to long range alpha/theta synchronization. International Journal of Psychophysiology 38: 301-313.

von Stein, A., Chiang, C., and König, P. 2000. Top-down processing mediated by interareal synchronization. Proceedings of the National Academy of Sciences USA 97: 14748-14753. 
Wallace, A. 1998. The Bridge of Quiescence: Experiencing Tibetan Buddhist Meditation. La Salle: Open Court.

Wallace, B.A. 1999. The Buddhist tradition of shamatha: methods for refining and examining consciousness. In F.J. Varela and J. Shear (eds.) The View from Within: First-Person Approaches to the Study of Consciousness, pp. 175-188. Thorverton, UK: Imprint Academic.

Watt, D.F. 1999. Emotion and consciousness: implications of affective neuroscience for extended reticular thalamic activating system theories of consciousness. Electronic publication of the Association for the Scientific Study of Consciousness. Available at: http://server.philvt.edu/assc/watt/default.htm

Wider, K.V. 1997. The Bodily Basis of Consciousness: Sartre and Contemporary Philosophy of Mind. Ithaca, NY: Cornell University Press.

Williams, P. 1998. The Reflexive Nature of Awareness. London: Curzon Press.

Zahavi, D. 1999. Self-Awareness and Alterity. Evanston, IL: Northwestern University Press.

Zahavi, D. 2002. First-person thoughts and embodied self-awareness: some reflections on the relation between recent analytic philosophy and phenomenology. Phenomenology and the Cognitive Sciences 1, 7-26.

Zahavi, D. 2003. Husserl's Phenomenology. Stanford, CA: Stanford University Press.

Zahavi, D. 2004. Intentionality and phenomenality: a phenomenological take on the hard problem. In E. Thompson (ed.), The Problem of Consciousness: New Essays in Phenomenological Philosophy of Mind. Canadian Journal of Philosophy Supplementary Volume. Calgary, AL: University of Alberta Press.

Zahavi, D. and Parnas, J. 1998. Phenomenal consciousness and self-awareness: a phenomenological critique of representational theory. Journal of Consciousness Studies 5: 687-705. 